\title{
The present and future offshore wind resource in the Southwestern African region
}

\author{
Daniela C. A. Lima ${ }^{1}$ (1) $\cdot$ Pedro M. M. Soares ${ }^{1} \cdot$ Rita M. Cardoso $^{1} \cdot$ Alvaro Semedo $^{2,3} \cdot$ William Cabos $^{4} \cdot$ Dmitry V. Sein $^{5,6}$
}

Received: 25 October 2019 / Accepted: 11 November 2020 / Published online: 2 January 2021

(c) Springer-Verlag GmbH Germany, part of Springer Nature 2021

\begin{abstract}
In the last decades, offshore wind harvesting has increased enormously, and is seen as a renewable energy resource with great potential in many regions of the world. Therefore, it is crucial to understand how this resource will evolve in a warming climate. In the present study, offshore wind resource in the Southwestern African region is analysed for the present and future climates. A ROM (REMO-OASIS-MPIOM) climate simulation in uncoupled and coupled atmosphere-ocean mode, at $25 \mathrm{~km}$ horizontal resolution, and a multi-model ensemble built with a set of regional climate models from the CORDEXAfrica experiment at $0.44^{\circ}$ resolution were used. The projected changes of the offshore wind energy density throughout the twenty-first century are examined following the RCP4.5 and RCP8.5 greenhouse gas emissions scenarios. Characterised by strong coastal-parallel winds, the Southwestern African offshore region shows high values of wind energy density at $100 \mathrm{~m}$, up to $1500 \mathrm{Wm}^{-2}$ near the coast, particularly offshore Namibia and west South Africa. Conversely, along Angola's coast the available offshore wind energy density is lower. Throughout the twenty-first century, for the weaker climate mitigation scenario (RCP8.5), an increase of the offshore wind resource is projected to occur along Namibia and South African western coasts, more pronounced at the end of the century $(+24 \%)$, while a decrease is projected along Angola's coasts, reaching a negative anomaly of about $-32 \%$. Smaller changes but with the same pattern are projected for the stronger climate mitigation scenario (RCP4.5). The future deployment of offshore floating hub turbines placed at higher heights may allow higher production of energy in this region. Along offshore Namibia and west South Africa, the wind energy density at $250 \mathrm{~m}$ showed differences that range between 30 and 50\% relative to wind energy density at $100 \mathrm{~m}$.
\end{abstract}

Keywords Wind offshore resource - Climate change - Eastern boundary current system · Southwestern African region . Regional climate modelling

Daniela C. A. Lima

dclima@fc.ul.pt

1 Faculdade de Ciências, Instituto Dom Luiz (IDL), Universidade de Lisboa, Campo Grande, Ed. C8 (3.), 1749-016 Lisbon, Portugal

2 IHE-Delft, Department of Water Science and Engineering, PO Box 3015, 2601DA Delft, The Netherlands

3 Faculdade de Ciências, Instituto Dom Luiz (IDL), Universidade de Lisboa, 1749-016 Lisbon, Portugal

4 Department of Physics and Mathematics, University of Alcalá, Alcalá de Henares, Madrid, Spain

5 Alfred Wegener Institute for Polar and Marine Research, Am Handelshafen 12, 27568 Bremerhaven, Germany

6 Shirshov Institute of Oceanology, Russian Academy of Science, 36 Nahimovskiy Prospect, Moscow, Russia 117997

\section{Introduction}

Under a warming climate, ambitious efforts and future goals have been put forward to reduce greenhouse gas emissions (Wiser et al. 2011). As a contribution to this climate change mitigation, the development of renewable energy resources (including wind power), in substitution of fossil fuels, has been increasing over the last decades. This growth is linked to recent technology maturity, large offshore wind potential available in vast coastal regions, and finally to the level of saturation in onshore wind harvesting. Barthelmie and Pryor (2014) explore the impact of the expansion of wind power deployment in the efforts to avoid the $+2{ }^{\circ} \mathrm{C}$ warming threshold. The authors not only show the significative impact of replacing coal by wind power, but also, that the warming threshold may be delayed by more than a decade if wind power and other strategies are implemented. 
The worldwide potential for wind energy exceeds the current global electricity production (Lu et al. 2009), although the distribution of the wind is not uniform around the globe. Due to different reasons, such as costs, favourable areas, etc., the wind resource is not a viable option in many countries, particularly offshore deployment. Additionally, being an intermittent energy resource, it typically needs a secondary energy technology to ensure safety of supply. Although the wind resource is available in most regions of the world, the majority of wind turbines are concentrated in Asia, Europe and North America (OECD/IEA 2013). In Europe, between 2008 and 2018, wind power grew from the 5th to the 2nd largest form of electric power generation, reaching a total installed wind power capacity of $189 \mathrm{GW}$, with $170 \mathrm{GW}(19 \mathrm{GW})$ installed onshore (offshore) (WindEurope 2019). Wind energy represents $37 \%$ of the electricity generation from renewable energy, which corresponds about $6 \%$ of the total electricity generation in United States (EIA 2019). Asia, China and India have the highest installed wind power capacity (Wiser et al. 2018). In those regions, onshore wind power has limited growth perspectives due to the high population density, which is also the case of United States. Therefore, despite higher costs, the offshore wind energy has become an important alternative to onshore wind energy, which has led to the recent fast increase in its deployment. The development of offshore wind power has been also motivated by other important factors, including greater potential around coastal areas with high wind speeds, noise and visual impacts reduction nearby population settlements and, the possibility to build larger wind power plants (Kaldellis and Kapsali 2013). Most wind power capacity is implanted in shallow waters, with depths around $20 \mathrm{~m}$ and a distance to the coast below $20 \mathrm{~km}$. Nevertheless, there is a clear trend to install offshore power plants at higher depths and further away from the coast, through the improvement of floating technologies (GWEC 2010, 2019). The development of larger wind turbines may lead to a reduction of offshore wind energy costs (Wiser et al. 2011). Currently, offshore floating wind turbines have hub-heights of around 70-100 $\mathrm{m}$, with a power capacity between 3 and $6 \mathrm{MW}$.

Eastern boundary current systems (EBCS) are located along the eastern flank of the five ocean gyres, including the California, Canary, Peru-Humboldt, Benguela and West Australia currents (Talley et al. 2011). In EBCS, atmosphere-land-ocean feedbacks play a crucial role in defining the regional climate. These regions are strongly influenced by intense coastal-parallel winds due to a sharp land-sea thermal gradient at the coast associated to higher temperatures over land and lower temperatures over ocean. The latter are connected to the presence of high-pressure systems over the ocean and the development of thermal lows inland. The EBCS are also characterised by a mesoscale wind feature designated as coastal low-level jets (CLLJs) driven by the sharp pressure gradient and intensified by the land-sea thermal contrast (Winant et al. 1988). CLLJs are characterised by a wind maximum within or at the top of the marine atmospheric boundary layer (Beardsley et al. 1987; Ranjha et al. 2013; Soares et al. 2014, 2019b; Lima et al. 2018). Due to higher values of wind speed within the atmospheric boundary layer, it is expected that, along EBCS, the offshore wind energy has a greater potential.

Global warming is expected to impact all regions of the world, including EBCS areas, which are considered as one of the most vulnerable to climate change (Sydeman et al. 2014; Bakun et al. 2015; Wang et al. 2015). An overall growth of the near-surface wind speed connected with the increase of the frequency of CLLJs occurrence is projected in the EBCS for the end of the twenty-first century (Semedo et al. 2016). For African EBCS, Benguela and Canaries, an increase of the near-surface flow along the coast is expected under a warming climate (Lima et al. 2019a; Soares et al. 2019a). In the Benguela EBCS, Lima et al. (2019a) showed that the projected increase of the near-surface wind speed and the Benguela's CLLJ frequency, is related to the intensification and south-easterly displacement of the South Atlantic highpressure system and to the strengthening of the land-ocean thermal contrast. Soares et al. (2019a) performed an analysis of the future changes on the North Africa CLLJ and found an intensification of the near-surface wind speed in coastal regions where the North Africa CLLJ is more persistent. Moreover, the authors showed an increase in the mean wind speed at the more prevalent jet heights. For the western coast of Iberia, Soares et al. (2014) characterised, for the first time, the climate change impact on the offshore wind resource. In this region (associated with the Canary EBCS), an increase of the near-surface wind speed associated with the northeasterly expansion of the Azores high-pressure system and the intensification of the Iberian thermal low is projected to occur (Soares et al. 2017b). An increase in the frequency and intensity of the Iberian Peninsula CLLJ is also projected. The authors showed a significative enhancement of the wind potential in summer, which counteracts the reduction in the remaining seasons.

Most studies concerning wind power in present and future climates are focused on the onshore wind power (Fant et al. 2016; Reboita et al. 2018; Nogueira et al. 2019). Further, studies analysing the offshore wind resource in a climate change context are scarce. Moreover, the expected development of offshore floating hub turbines towards higher altitudes may allow more energy production in regions where CLLJs occur. Hence, it is important to understand the future evolution of the offshore wind resource, especially in EBCS regions, where this resource is little explored, as in offshore Southwestern Africa. To the best of our knowledge, an offshore wind power study was never performed for this region. The main aim of the current study is to investigate 
the offshore wind resource potential in present and future climates in the Southwestern African offshore region (along Angola, Namibia and South Africa coasts). For the first time in this region, atmospheric and ocean models are coupled and produce a 3D depiction of the atmosphere at high temporal and spatial resolution $\left(0.25^{\circ}\right)$ and for a climatological scale (60 years) (Sein et al. 2015). Due to the strong coupling between the atmosphere and the ocean surface in these regions, these simulations represent the state-ofthe-art regarding weather and climate. However, these two runs rely on the same atmospheric model, which is short for a climate change assessment study. In order to provide robustness to the study and in addition to the coupled simulation, an uncoupled simulation with the same settings of the first and, state-of-the-art regional climate simulations from Coordinated Regional Climate Downscaling experiment over Africa (CORDEX-Africa; Giorgi et al. 2009; Hewitson et al. 2012) are also used. Note that all these simulations are performed with atmospheric models, which in many cases, are also used for weather forecasting and embody the best representation of the atmospheric 3D circulation to date. The novelty of the current study is the use of a regional coupled simulation to explore the impact of climate change on the offshore wind resource taking in account the air-sea coupling on changes in wind power. The coupled simulations can be essential to represent the ocean processes in regions with important atmosphere-ocean feedbacks.

The present study intends to answer to the following questions: (1) What is the present offshore wind resource in the Southwestern African region at a typical hub-height of $100 \mathrm{~m}$ height? (2) How will the offshore wind resource be affected by global warming? and (3) What will be the impact of higher hub-heights in regions of maximum Benguela CLLJ occurrence?

This paper is organised as follows: Sect. 2 presents the model, simulations and methodology; the climatology of the offshore wind resource and the impacts of climate change are described in Sect. 3, and the main conclusions are outlined in Sect. 4.

\section{Data and methods}

\subsection{CORDEX-Africa simulations}

CORDEX encompasses a set of regional climate simulations over Africa (Hewitson et al. 2012), which are used here to characterise the offshore wind resource in present and future climates (Fig. 1a). Only daily mean near-surface wind speed is used since the wind speed at model levels is not available. A total of 19 CORDEX-Africa simulations (available through the web portal of the Earth System Grid Federation: http://esg-dn1.nsc.liu.se/esgf-web-fe/live) with a horizontal resolution of $0.44^{\circ}$ were used for the historical climate period (1976-2005) and for two future climate periods, the mid-twenty-first century (2040-2069) and the end twenty-first century (2070-2099). The future climate is investigated under two different greenhouse gas emissions scenarios, following the Representative Concentration Pathways (RCP), RCP4.5 and RCP8.5 (Moss et al. 2010; van Vuuren et al. 2011; Riahi et al. 2011). The CORDEXAfrica RCM simulations used are presented in Table 1, with the respective Global Climate Model (GCM) forcing. The CORDEX-Africa simulations have been extensively evaluated for present climate; e.g.: precipitation (Nikulin et al. 2012; Kalognomou et al. 2013), temperature (Kim et al. 2014; Panitz et al. 2014), surface fluxes (Careto et al. 2018) and offshore wind speed (Lima et al. 2019a, b; Soares et al. 2019a, b). Overall, the RCM simulations are able to represent the continent's climate.

\subsection{ROM simulations}

In the current study we analyse four regional climate simulations produced with the coupled system model ROM (REMO-OASIS-MPIOM) (Sein et al. 2015). In this system, the OASIS coupler is used to couple the Regional Atmospheric Model (REMO; Jacob et al. 2001), the global oceanic model Max Planck Institute Ocean Model (MPIOM), the Hamburg Ocean Carbon Cycle (HAMOCC) Model and the Hydrological Discharge (HD) Model. Here, we examine simulations for historical climate from 1976 to 2005 and future climate (following the RCP8.5 scenario) from 2070 to 2099, in stand-alone atmosphere mode and in atmosphere-ocean coupled mode. These simulations were forced by the MaxPlanck Institute Earth System Model (MPI-ESM) as lateral boundary conditions (Giorgetta et al. 2013) both in coupled and uncoupled runs. The atmospheric component of ROM (REMO) has a $25 \mathrm{~km}$ horizontal resolution, with 31 hybrid vertical levels, covering the African continent, a large part of Atlantic Ocean, the Mediterranean region, and parts of the Indian Ocean (Fig. 1b). In both uncoupled and coupled simulations, the atmospheric component of the MPI-ESM is used to force the lateral boundary conditions of REMO. The atmospheric component of MPI-ESM is used to force MPIOM outside of the region of coupling (that coincides with the REMO domain).

\subsection{Observations}

The 10-m wind speed from the Cross-Calibrated Multi-Platform (CCMP) data set (Atlas et al. 2011) is used to compute the offshore wind resource and evaluate the RCM simulations. CCMP was developed by NASA (National Aeronautics and Space Administration) and it has 6-hourly output at $0.258^{\circ}$ of horizontal resolution. This wind product spans 
(a)

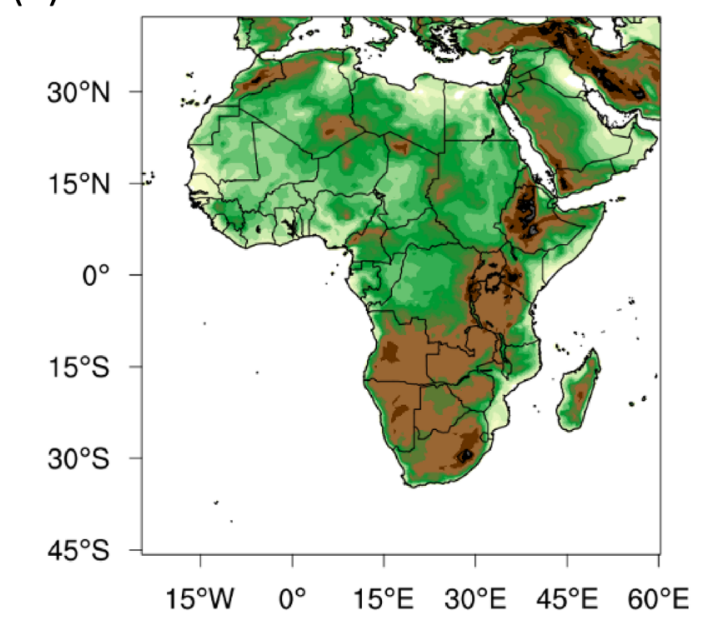

(c)

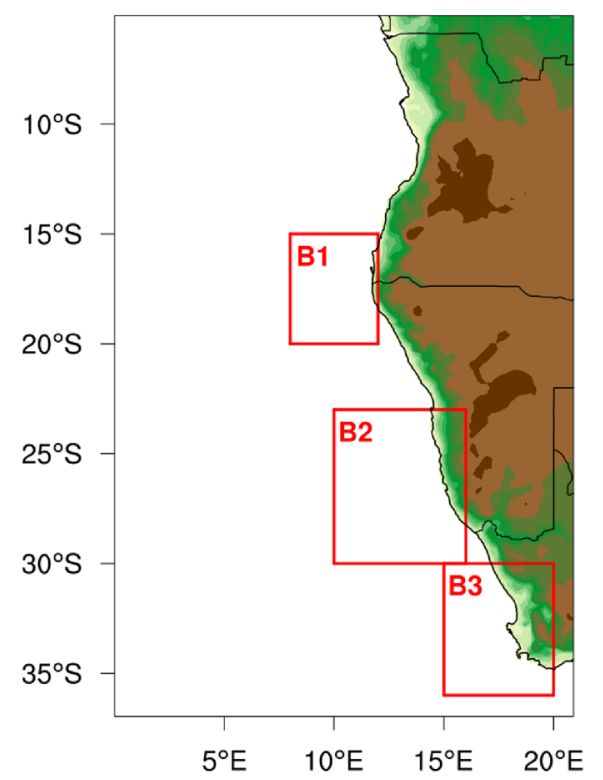

(b)

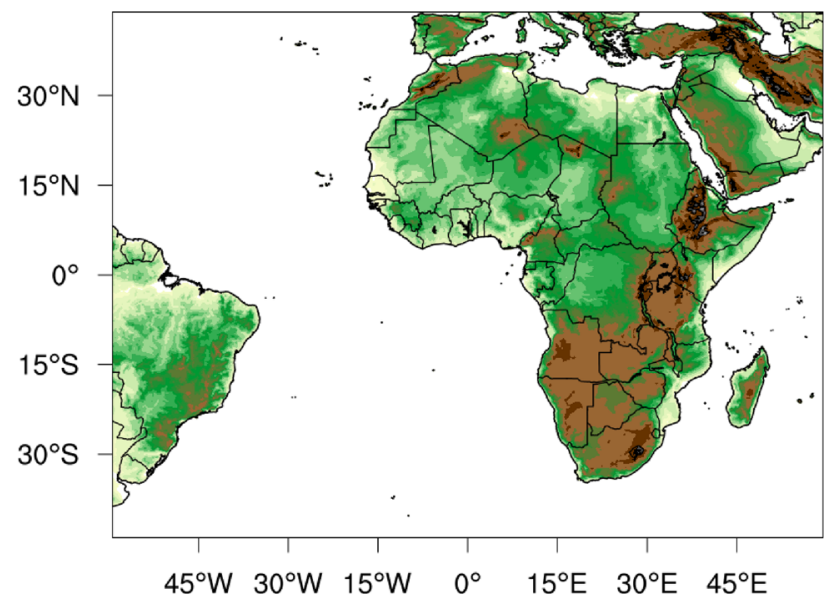

Fig. 1 a CORDEX-Africa domain, b ROM Model domain and $\mathbf{c}$ a zoom over the Southwestern African offshore region. Solid red line delimits the areas B1, B2 and B3 of analysis regarding the offshore wind resource

from July 1987 to June 2011, without gaps. Through a variational analysis method, the cross-calibrated multiple satellite datasets were combined with remote sensing, in situ observations and reanalysis data from the European Centre of Medium-Range Weather Forecasts (ECMWF).

In Lima et al. (2019a), a qualitative and quantitative assessment of the 10-m wind speed from the uncoupled and coupled ROM simulations, and CORDEX-Africa simulations against the CCMP dataset was performed. Based on this assessment, a CORDEX-Africa multi-model ensemble weighted mean (EnsFull) was built by aggregating each RCM's wind speed multiplied by the RCM's respective weight [see more details about the ensemble building and the evaluation process in Lima et al. (2019a)].
This EnsFull is used in the current study. Lima et al. (2019a) showed that the coupled ROM and the EnsFull near-surface wind fields have the best agreement when compared with observations, giving confidence to the use of the ensemble in this study.

\subsection{Wind offshore resource}

The offshore wind resource is characterised by the wind energy density. Here we consider a typical hub-height of $100 \mathrm{~m}$. Accordingly to Pryor and Barthelmie (2011), the instantaneous wind energy density $E$, equivalent to the wind power per square meter $P / A$, is computed as: 
Table 1 Regional climate models from CORDEX-Africa used in the present study with the respective global climate model forcing

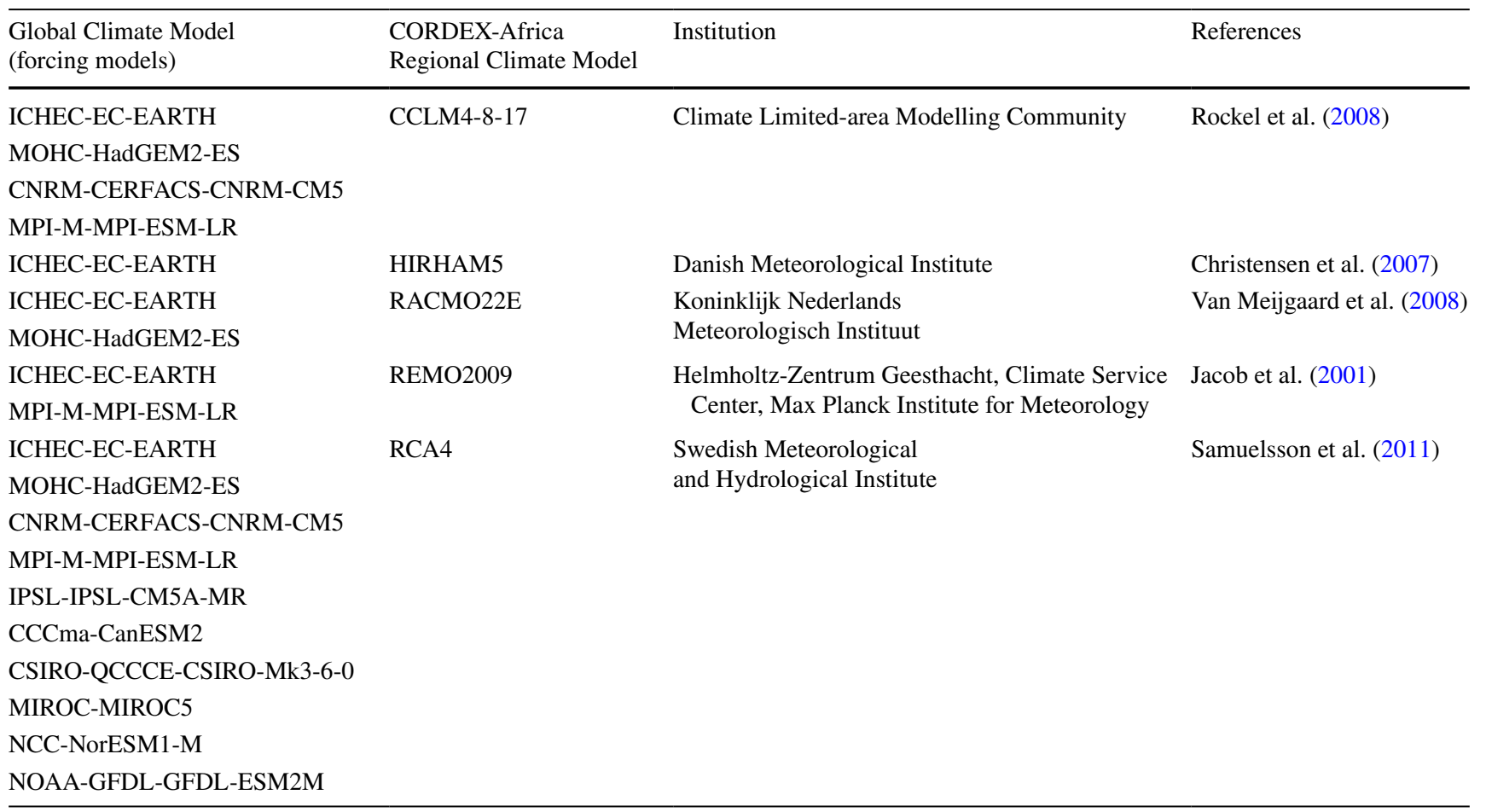

$E=\frac{P}{A}=\frac{1}{2} \rho v_{z}^{3}$

where the $\rho$ is the air density considered as a constant value of $1.2 \mathrm{~kg} \mathrm{~m}^{-3}$, in agreement with a standard atmosphere from the International Organization for Standardization. Most wind turbines do not produce electrical power below (cut-in) wind speeds around $3 \mathrm{~ms}^{-1}$ and higher than $25 \mathrm{~ms}^{-1}$ (cut-out). The wind energy density is computed at $100 \mathrm{~m}$ height, for wind speeds between 3 and $25 \mathrm{~ms}^{-1}$, with the aim of performing a climate change assessment of the offshore wind resource, considering its spatial and temporal variabilities.

Since the CCMP is a near-surface wind product and the RCMs from CORDEX-Africa do not have model level data available, the 100-m wind speed is computed for these simulations using the logarithm wind profile extrapolation (Eq. (2)) (Yamada and Mellor 1975).

$v_{z}=v_{z_{m}} \ln \left(\frac{z}{z_{0}}\right) / \ln \left(\frac{z_{m}}{z_{0}}\right)$

$v_{z}$ corresponds to the wind speed at a height $z, v_{z_{m}}$ is the wind speed at the standard height of $10 \mathrm{~m}$ and $z_{0}$ is the local roughness length with a constant value of $1.52 \times 10^{-4}$ $m$ over the ocean surface (Carvalho et al. 2014). In the case of ROM simulations, the wind speed at model levels are used to interpolate and compute the 100-m wind speed.

\subsection{Methods}

Firstly, a characterisation of the offshore wind speed and wind energy density at $100 \mathrm{~m}$ height are performed along the Angolan, Namibian and South African coasts for the present climate, using the uncoupled and coupled ROM simulations and a CORDEX-Africa multi-model ensemble. Secondly, the impact of the climate change on the properties of the wind resource is investigated towards the end of the twentyfirst century. The wind resource at higher hub-heights is also explored in the regions where the Benguela CLLJ is more frequent.

Three coastal areas where the wind speed has higher values are chosen. These areas are defined with red boxes in Fig. 1c, in agreement with the areas where the Benguela CLLJ has higher frequency of occurrence (Lima et al. 2019a).

In Fig. 2, a flowchart illustrates the methodology used connected with the paper's structure.

\section{Results}

\subsection{Present climate}

The offshore Southwestern Africa annual and seasonal wind speed and wind energy density at $100 \mathrm{~m}$ height are depicted 


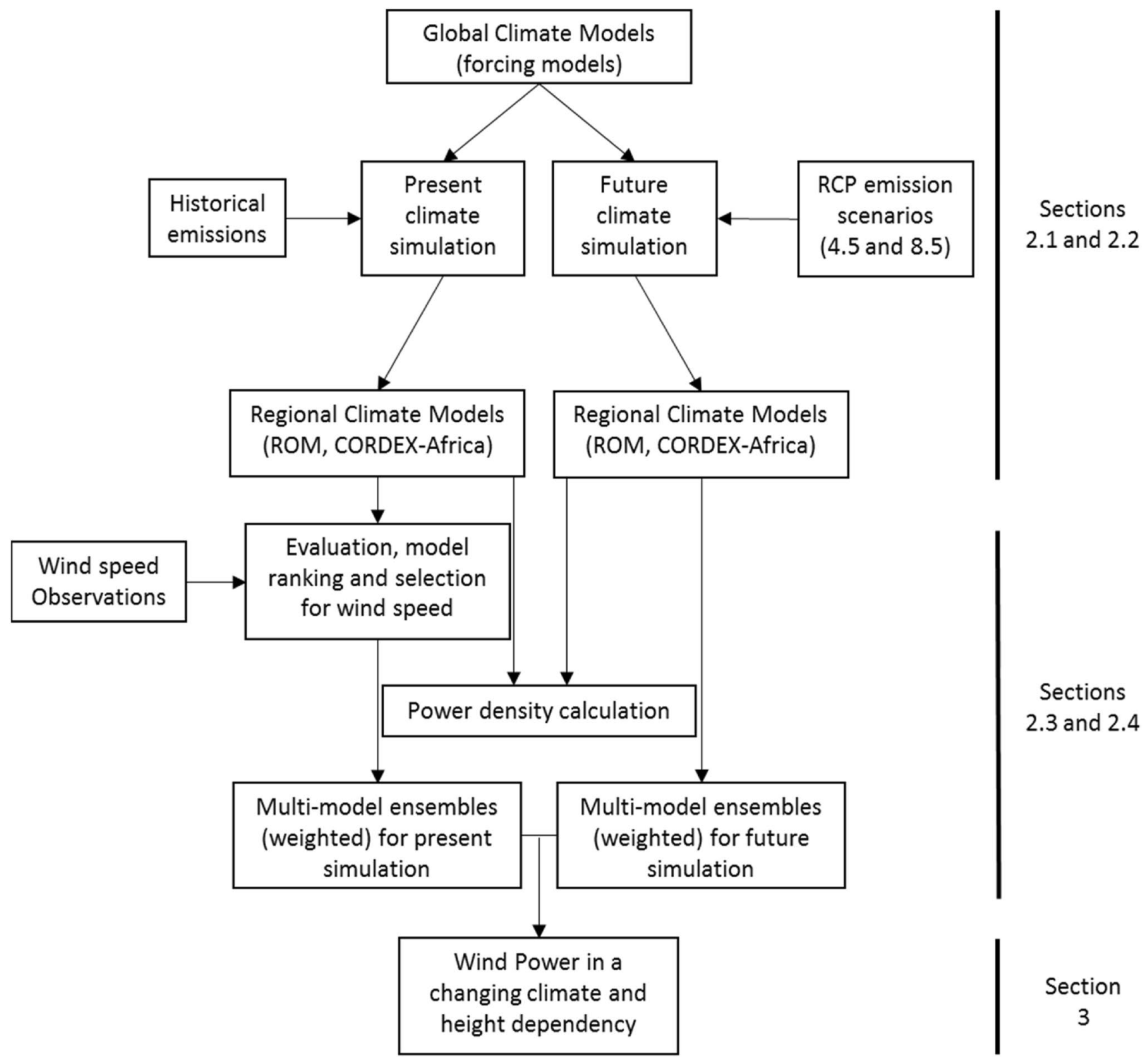

Fig. 2 Methodology flowchart

in Figs. 3 and 4, respectively and Fig. 5 shows the probability density function (PDF) for the 100-m wind speed. As expected, the spatial patterns of the wind energy density and wind speed at $100 \mathrm{~m}$ height are rather similar. In all seasons, the offshore wind speed reveals a meridional wind speed gradient, ranging between 8 and $12 \mathrm{~ms}^{-1}$ along Namibia and west South Africa coasts and $4 \mathrm{~ms}^{-1}$ along the coast of Angola. An annual cycle is clear in observations and models, with the highest wind speeds occurring during the austral summer and spring seasons (DJF-December, January and February and SON-September, October and November, respectively). This annual cycle is also clearly present in the wind speed maxima position, which is related with the presence of the Benguela CLLJ (Lima et al. 2019a, b). During summer and spring, a maximum value of wind speed around $12 \mathrm{~ms}^{-1}$ is found near $26^{\circ} \mathrm{S}$. In winter (JJA-June, July and August), the wind speed maximum is located around $17.5^{\circ} \mathrm{S}$ with a value of about $10 \mathrm{~ms}^{-1}$. Along the coast, the wind speed spatial pattern is rather similar between both ROM simulations (uncoupled and coupled) and the EnsFull. Nevertheless, the uncoupled ROM run has slightly lower wind speed values. The spatial patterns of the wind speed are comparable between observations and models, however the flow interaction with the coast is not clear in the CCMP. This is related to the known problems that this product shows near the coast, due to the influence of 

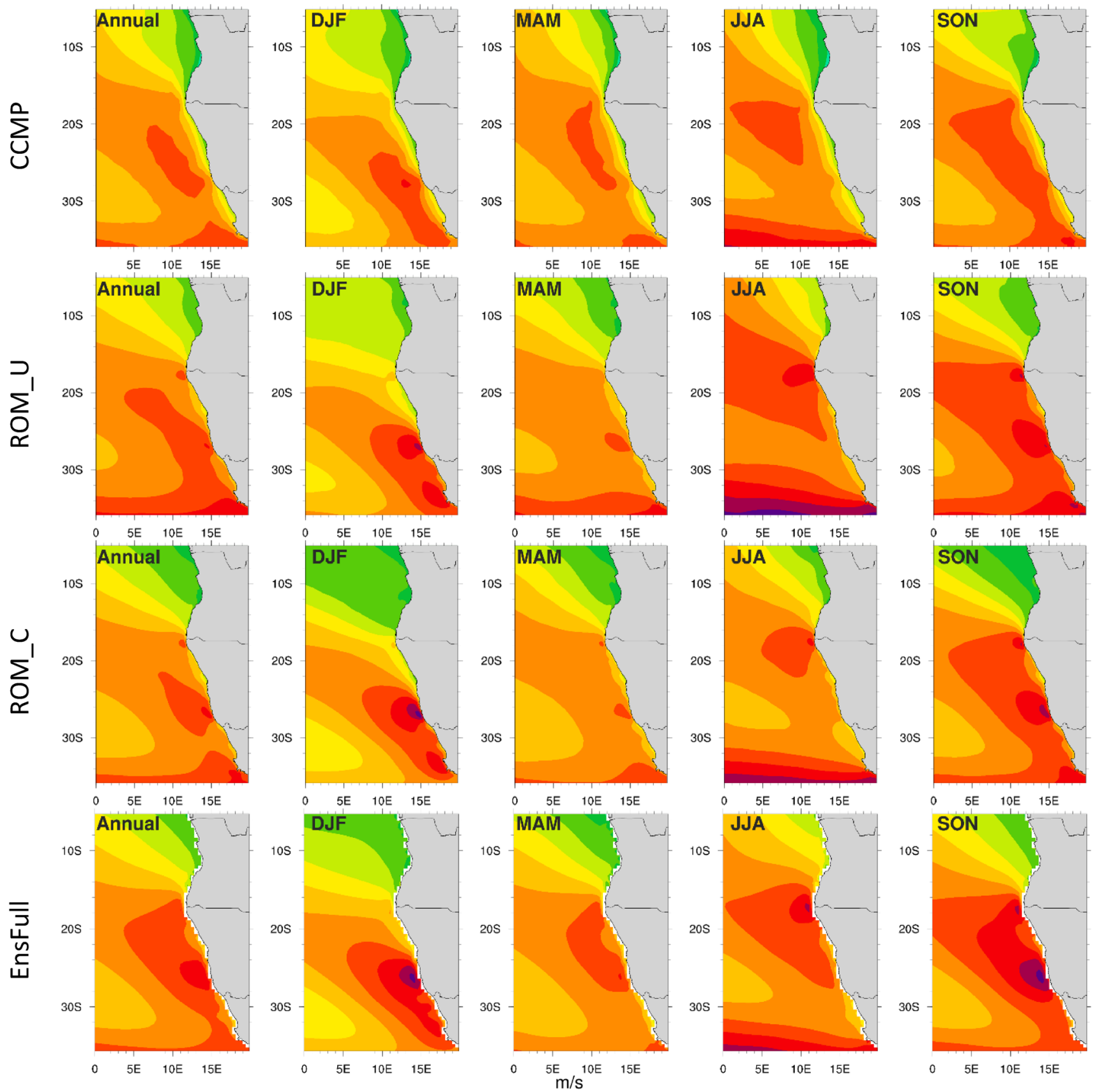

Fig. 3 Annual and seasonal wind speed means $\left(\mathrm{ms}^{-1}\right)$ at $100 \mathrm{~m}$ height for the CCMP (1988-2011), the uncoupled (ROM_U) and coupled (ROM_C) ROM runs and the EnsFull, for the historical period (1976-2005)

the backscatter from land that contaminates the wind speed measures closer to the coast (Tang et al. 2004).

In order to analyse the uncertainties between RCMs, the PDFs of wind speed at $10 \mathrm{~m}$ height are depicted in Fig. 5 for each of the selected areas. In the three areas, the models present an overestimation of the occurrence of wind speeds higher than $10 \mathrm{~ms}^{-1}$ and an underestimation of the occurrence of wind speeds in the range of $1-10 \mathrm{~ms}^{-1}$. These results are in agreement with the PDFs presented in Lima et al. (2019a) for a region encompassing these three study areas. The distribution of the near-surface wind speed values is rather similar between both ROM simulations and there is a slight shift for higher values for the EnsFull wind speed distribution in area B3. Looking at the distribution 


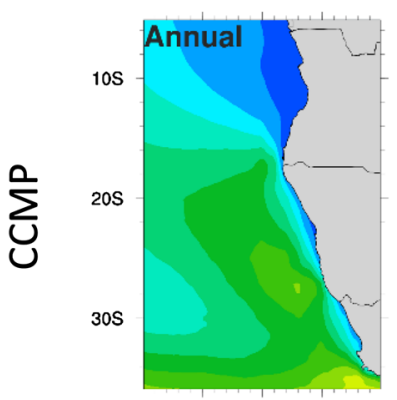

$5 E \quad 10 E \quad 15 E$
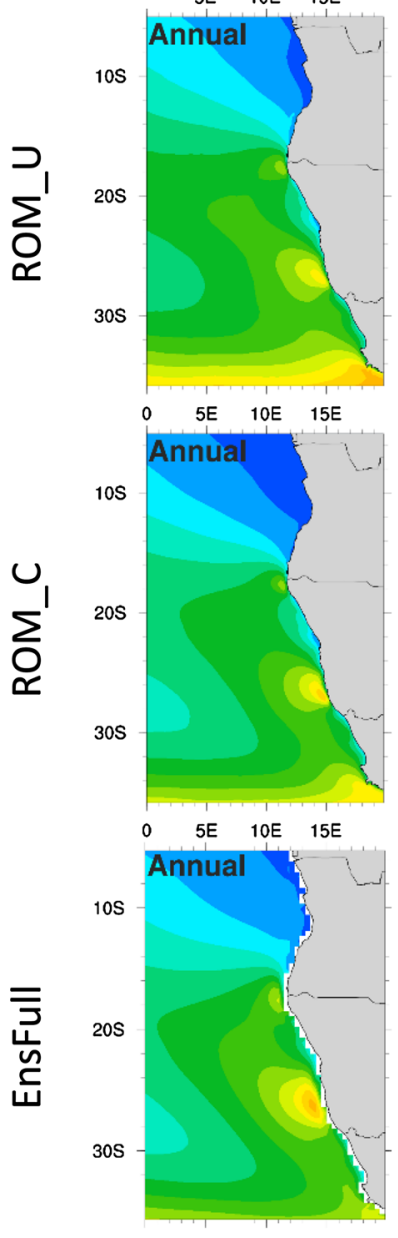

- 5E $\quad 10 \mathrm{E} \quad 15 \mathrm{E}$

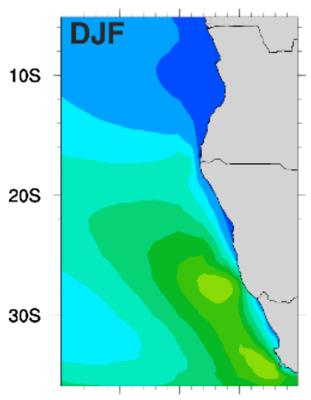

$5 E \quad 10 E \quad 15 E$
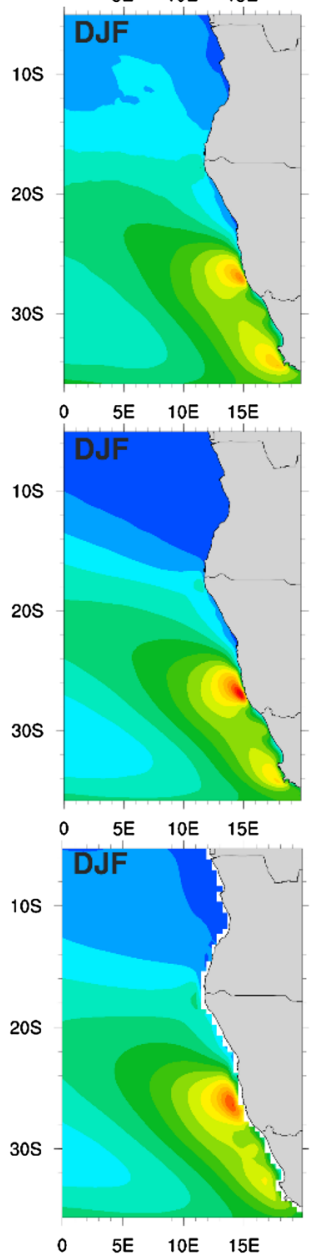

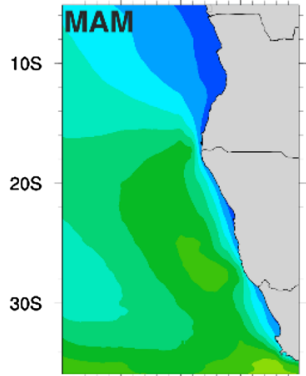

$5 E \quad 10 E \quad 15 E$

$10 S$
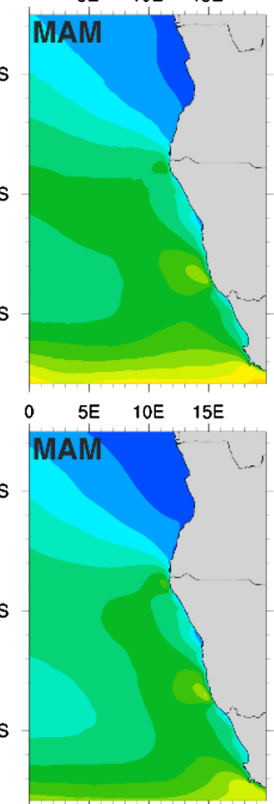

$10 S$
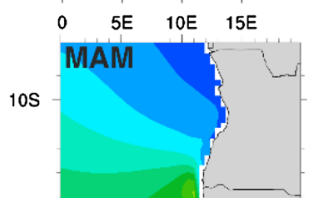

$20 S$

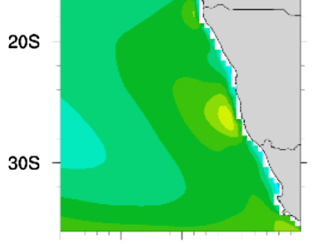

- 5E 10E 15E

$\mathrm{W} / \mathrm{m} 2$

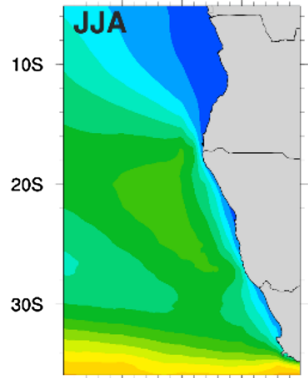

$5 E \quad 10 E \quad 15 E$

$10 S$

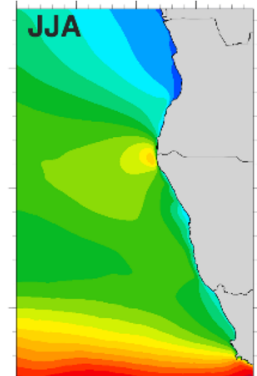

o 5E 10E 15E

$10 \mathrm{~S}$
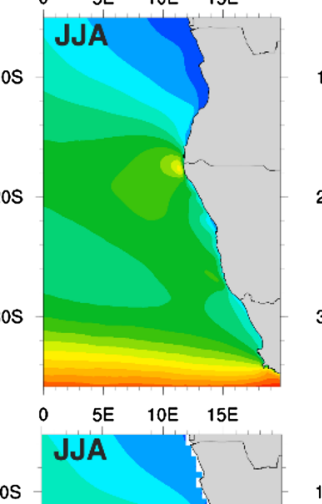

$10 \mathrm{~S}$

$20 S$

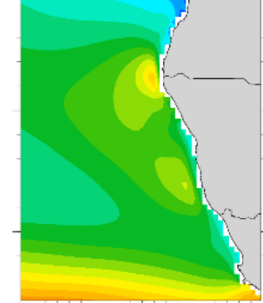

$5 E \quad 10 E \quad 15 E$

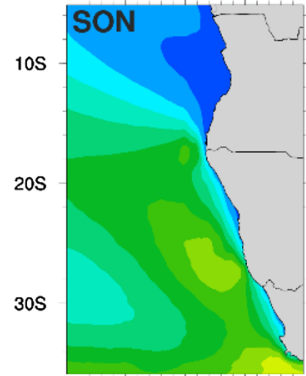

$5 E \quad 10 E \quad 15 E$
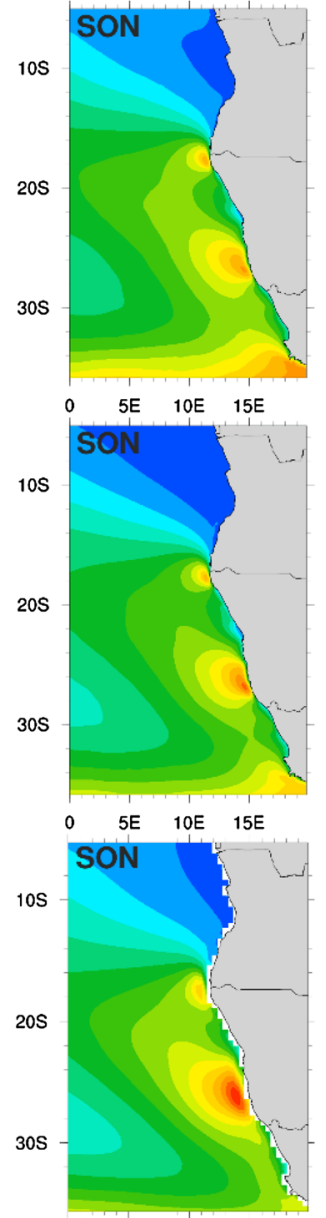

o $5 E \quad 10 E \quad 15 E$

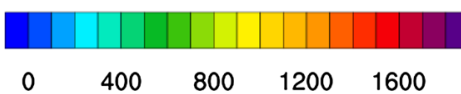

Fig. 4 Annual and seasonal wind energy density $\left(\mathrm{Wm}^{-2}\right)$ at $100 \mathrm{~m}$ height for the CCMP (1988-2011), for the uncoupled and coupled ROM runs and for the CORDEX-Africa multi-model ensemble, for the historical period (1976-2005)

of each CORDEX-Africa RCMs, the models represent reasonably well the $10-\mathrm{m}$ wind speed distribution and the spread between them is not large. In the three areas, the wind speed median values are found between 8 and $10 \mathrm{~ms}^{-1}$ for the EnsFull and in the range of 7 and $9 \mathrm{~ms}^{-1}$ in both ROM simulations. The occurrence of strong wind speeds (higher than $10 \mathrm{~ms}^{-1}$ ) is higher in area B2 and the incidence of wind speeds above $25 \mathrm{~ms}^{-1}$ is almost negligible in all areas. Also, about $95 \%$ of occurrences have wind speeds higher than $3 \mathrm{~ms}^{-1}$.

The wind energy density spatial pattern reveals the locations and the seasons where the offshore wind resource has 

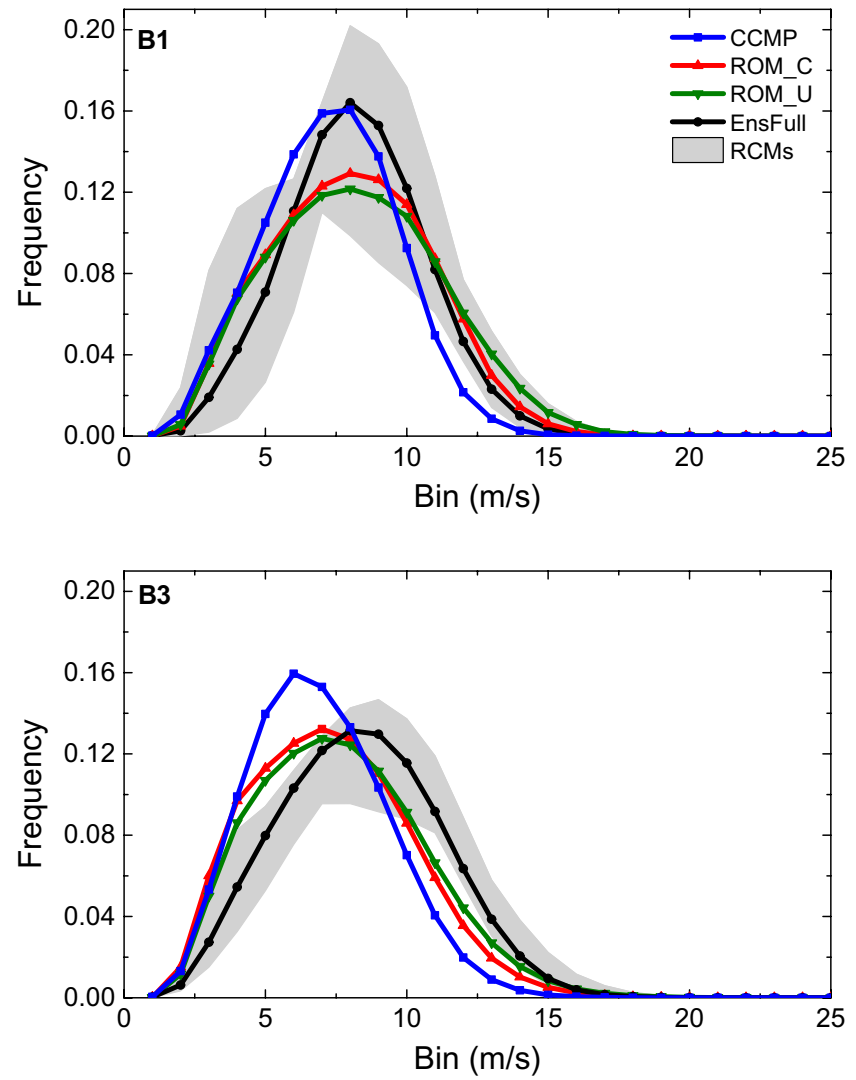

Fig. 5 Probability density function of wind speed at $10 \mathrm{~m}$ height given by CCMP (blue), uncoupled (green) and coupled (red) ROM simulations and CORDEX-Africa multi-model ensemble (black).

higher available potential. Offshore Namibia and South Africa western coasts, the wind energy density presents values ranging from 700 to $1500 \mathrm{Wm}^{-2}$ in all seasons. Along the Angola coast, the offshore wind resource does not exceed $400 \mathrm{Wm}^{-2}$. Though, there are specific coastal areas where the wind energy density has maximum values. During summer and spring, a maximum value of about $1400 \mathrm{Wm}^{-2}$ is found around $26^{\circ} \mathrm{S}$. At the same location, during winter (JJA) and autumn (MAM-March, April and May), the wind energy density does not exceed $1000 \mathrm{Wm}^{-2}$. Finally, around $17.5^{\circ} \mathrm{S}$ the mean wind energy density has values in the range of $1000-1100 \mathrm{Wm}^{-2}$. As for wind speed, the areas where higher values of wind energy density are found correspond to the areas of maximum frequency of occurrence of the Benguela coastal jet (Lima et al. 2019b). In Soares et al. (2017a), where the characterisation of the offshore wind resource along the western Iberian Peninsula coast is presented, a similar link between the CLLJ and the wind resource is presented. These results show that the areas where CLLJs are more prevalent are also the areas where the potential for the wind renewable energy is highest.

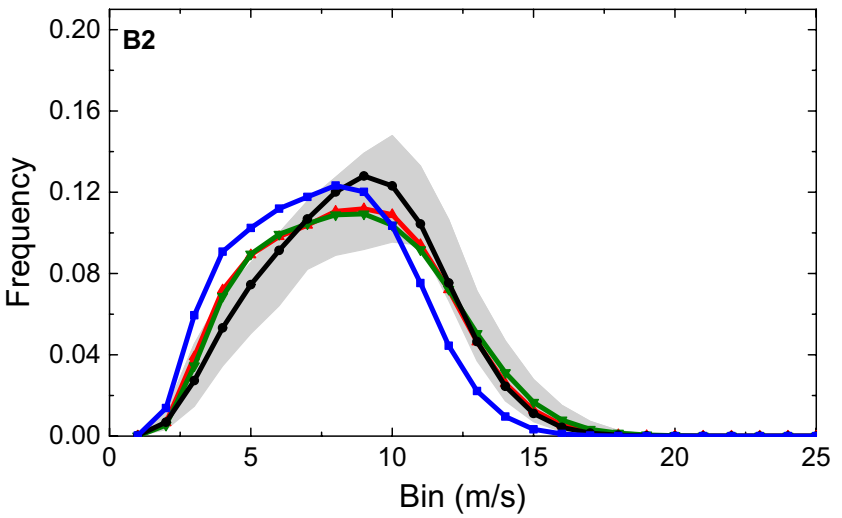

The shading grey area represents the spread of 19 CORDEX-Africa RCMs. The PDFs are for areas B1, B2 and B3 (red boxes in Fig. 1c)

\subsection{Future climate}

\subsubsection{Mid-twenty-first century (2040-2069)}

Figure 6 illustrates the annual and seasonal mean wind energy density at $100 \mathrm{~m}$ projected changes for mid-twentyfirst century, from the EnsFull (relative changes: future minus present divided by the present time slices; in percentage). It is important to keep in mind that ROM simulations do not have this time period. For convenience, from here onwards, all projected relative changes will only be referred as "projected changes". For all the projected changes a Student's $t$ statistical significance test has been applied. The shaded areas specify changes non statistically significant at a $90 \%$ confidence level.

The EnsFull mean wind energy density shows small to moderate projected changes in both greenhouse gas emissions scenarios. During summer, a slight increase between +4 and $+8 \%$ offshore west South Africa is predicted, although it is larger for RCP8.5, close to $+16 \%$. However, along the coast of Angola, a small reduction between -4 to $-8 \%$ and -8 to $-12 \%$ is found in RCP4.5 
and RCP8.5 scenarios, respectively, in all seasons except during autumn.

\subsubsection{Late twenty-first century (2070-2099)}

Projected changes for the end of the twenty-first century, from ROM simulations (uncoupled and coupled) and the EnsFull for the annual and seasonal wind energy density mean at $100 \mathrm{~m}$ are depicted in Fig. 7.

For the RCP4.5 scenario, a slight increase of the offshore wind resource in the range of +4 and $+8 \%$ offshore west South Africa is projected during summer. The EnsFull projected changes for the annual mean wind energy density pattern shows a small reduction of $-4 \%$ along the coast of Angola. The projected changes of the offshore wind resource present a small decrease between -4 and $-8 \%$ along the coast of Namibia. On the other hand, in winter and spring, a decrease of about $-8 \%$ is projected along offshore Angola, as shown by the annual EnsFull projected changes.

Regarding the RCP8.5 scenario, the overall projections of wind energy density present a similar pattern for both ROM simulations and EnsFull. To illustrate the uncertainties in the projected changes, the $100-\mathrm{m}$ wind speed seasonal delta changes between the future climate (2070-2099, following the RCP8.5 scenario) and the historical climate (1976-2005) for each area are represented in Fig. 8. The projections for the annual mean reveal an increase in the range of +4 and $+12 \%$ offshore Namibia and west South Africa. During summer, all simulations project an enhancement of the mean wind energy density offshore west South Africa reaching values of $+24 \%$. Looking at the $100-\mathrm{m}$ wind speed changes, projected by individual models, for the area B3, more than $90 \%$ of models display an increase, giving robustness to the results. An increase is also projected offshore Namibia in winter, reaching values around $+16 \%$ and $+20 \%$. The ROM coupled simulation shows a higher offshore extent of the projections of wind energy density than the ROM uncoupled and EnsFull. More than $80 \%$ of individual models agree in the projected signal, supporting the significant increase of the wind energy density in area B2. In spring, the ROM uncoupled run has statistically significant projected changes offshore Namibia, with an increase of about $+24 \%$. The ROM coupled and EnsFull present a slight increase between 4 and $8 \%$. Furthermore, only $73 \%$ of individual models display a positive signal, which does not reach the $80 \%$ threshold considered for robustness. Along the Angola's coast,

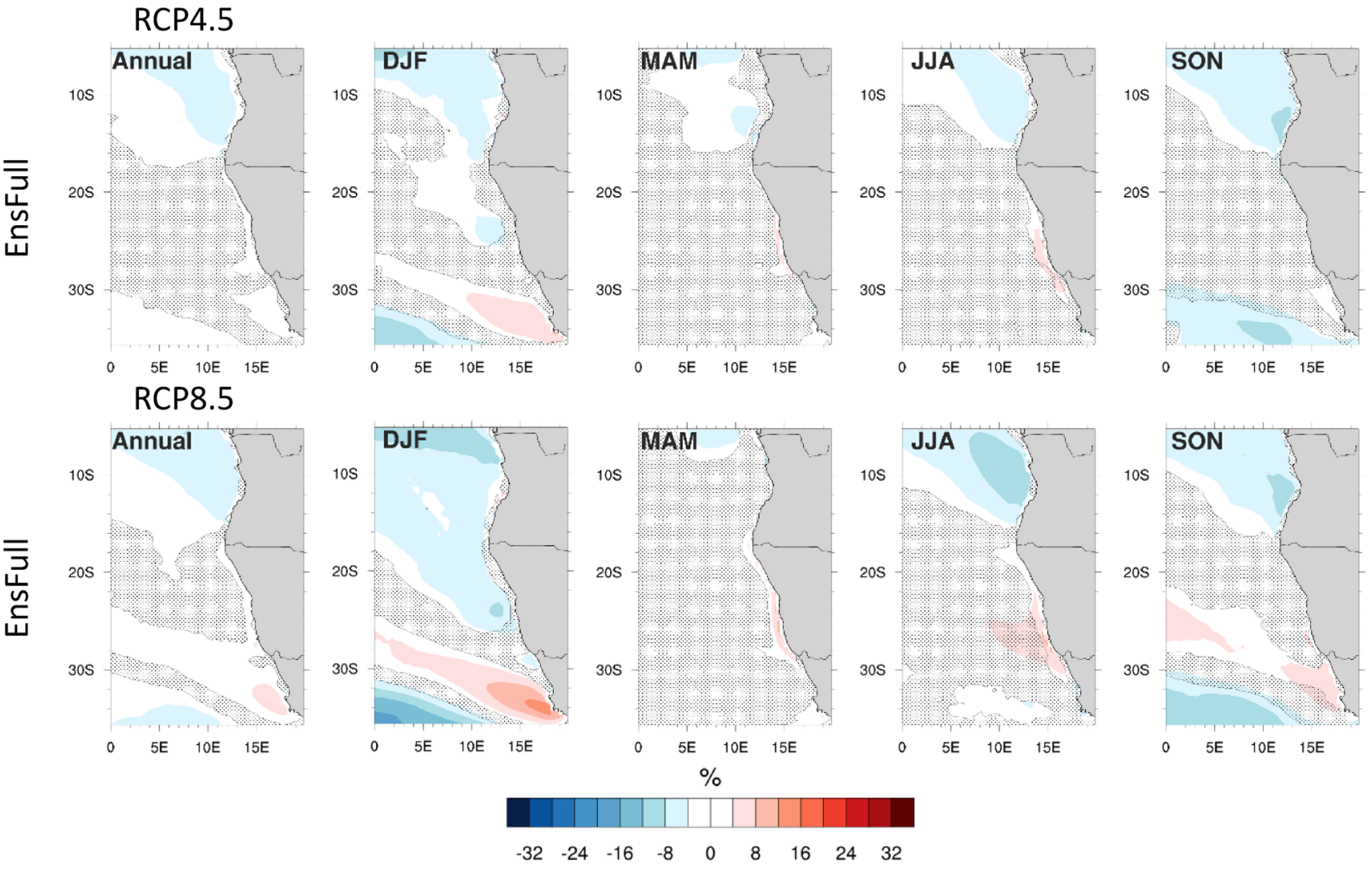

Fig. 6 Projected relative changes of the annual and seasonal mean wind energy density at $100 \mathrm{~m}$ height between historical and future mid-century under the scenarios RCP4.5 and RCP8.5 (2040-2069 minus 1976-2005)/(1976-2005), from the CORDEX-Africa multimodel ensemble. Shaded areas specify changes not statistically significant using a Student's $t$-test at the $90 \%$ confidence level 
RCP4.5

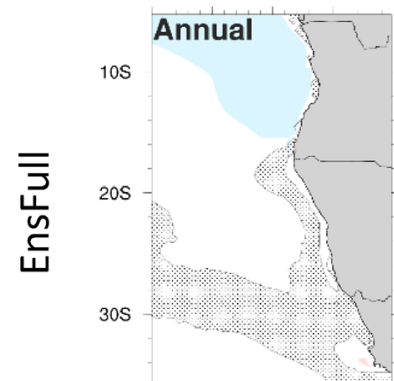

- 5 E $10 \mathrm{E} \quad 15 \mathrm{E}$

RCP8.5
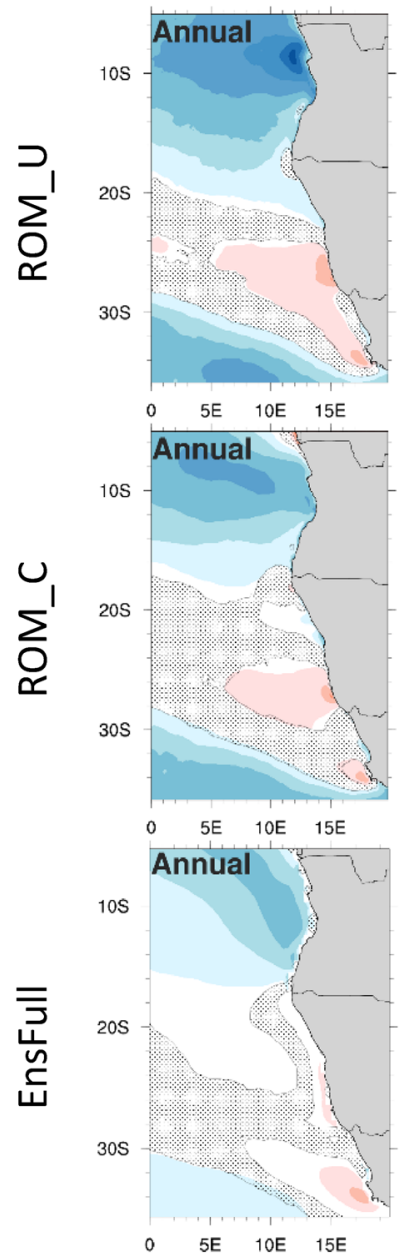
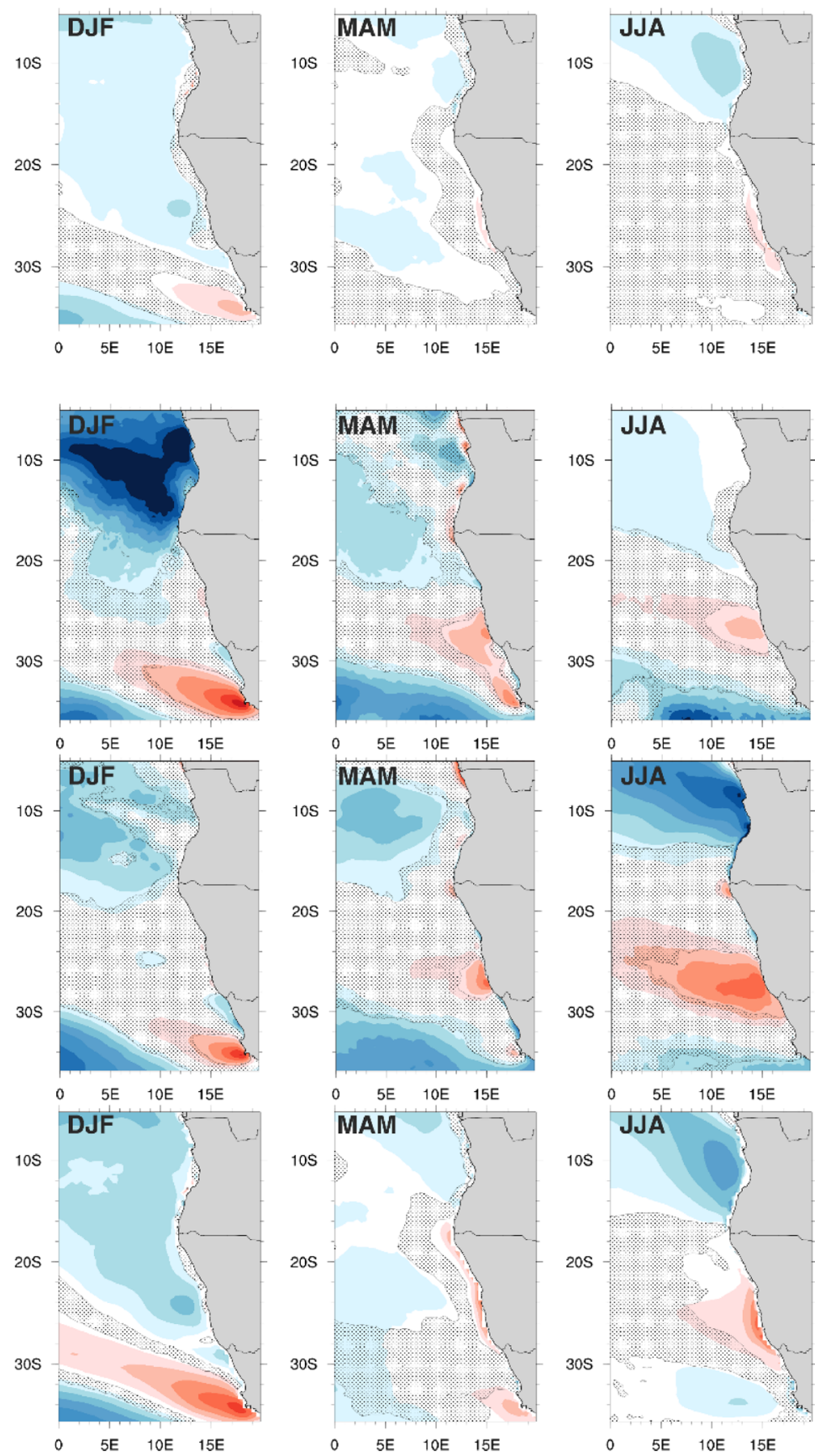
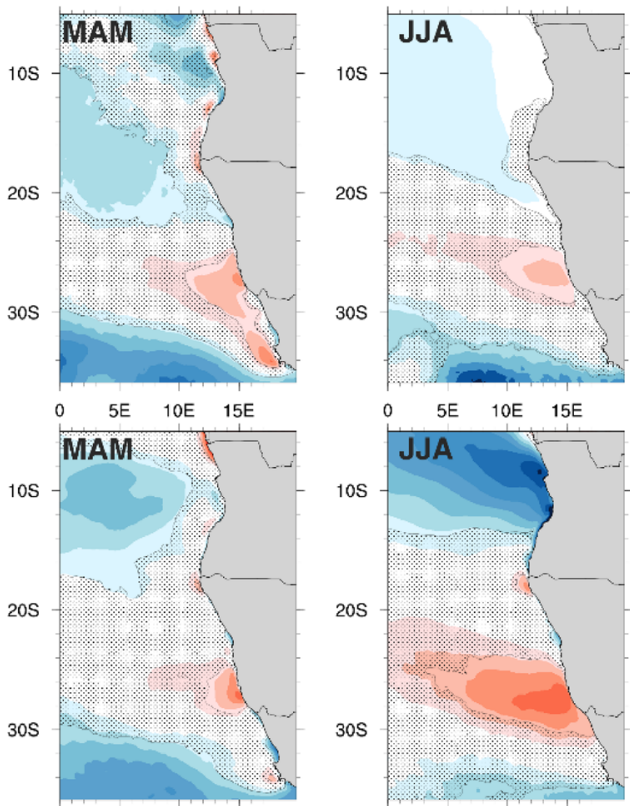

$10 \mathrm{~S}$
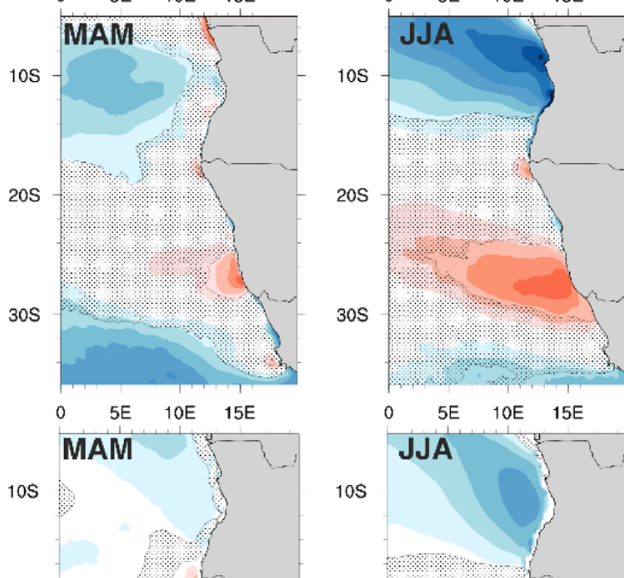

$10 S$
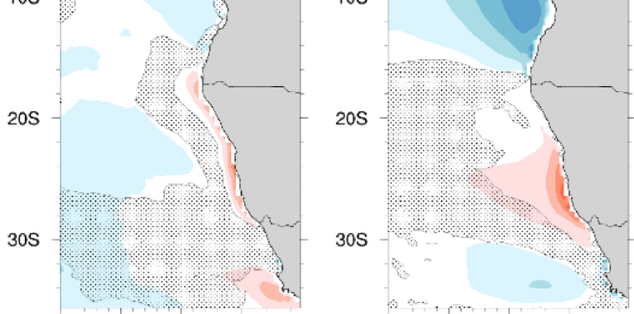

$\%$
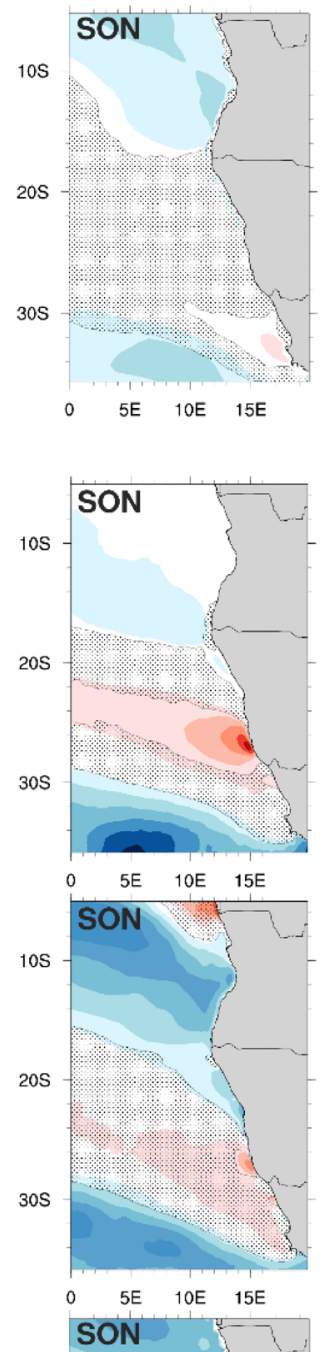

$10 \mathrm{~s}$

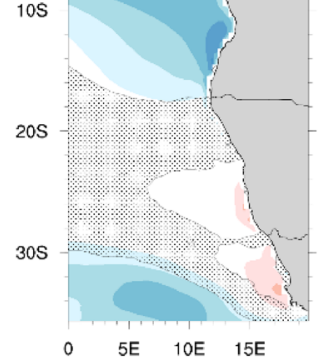

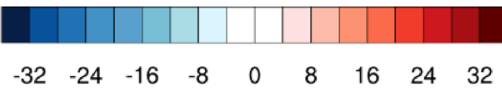

Fig. 7 Projected relative changes of the annual and seasonal mean wind energy density at $100 \mathrm{~m}$ height between historical and future end-century under the scenarios RCP4.5 and RCP8.5 (2070-2099 minus 1976-2005)/(1976-2005), from ROM simulations and from the CORDEX-Africa multi-model ensemble. Shaded areas specify changes not statistically significant using a Student's $t$-test at the $90 \%$ confidence level the annual mean displays a significant decrease of the wind energy density, in the range of -12 and $-16 \%$, although the uncoupled ROM simulation shows decreases of around
$-28 \%$. Here, a significant reduction $(-32 \%)$ is projected in the uncoupled ROM simulation during summer. This anomaly is related to the increase of the sea surface temperature 
(a)
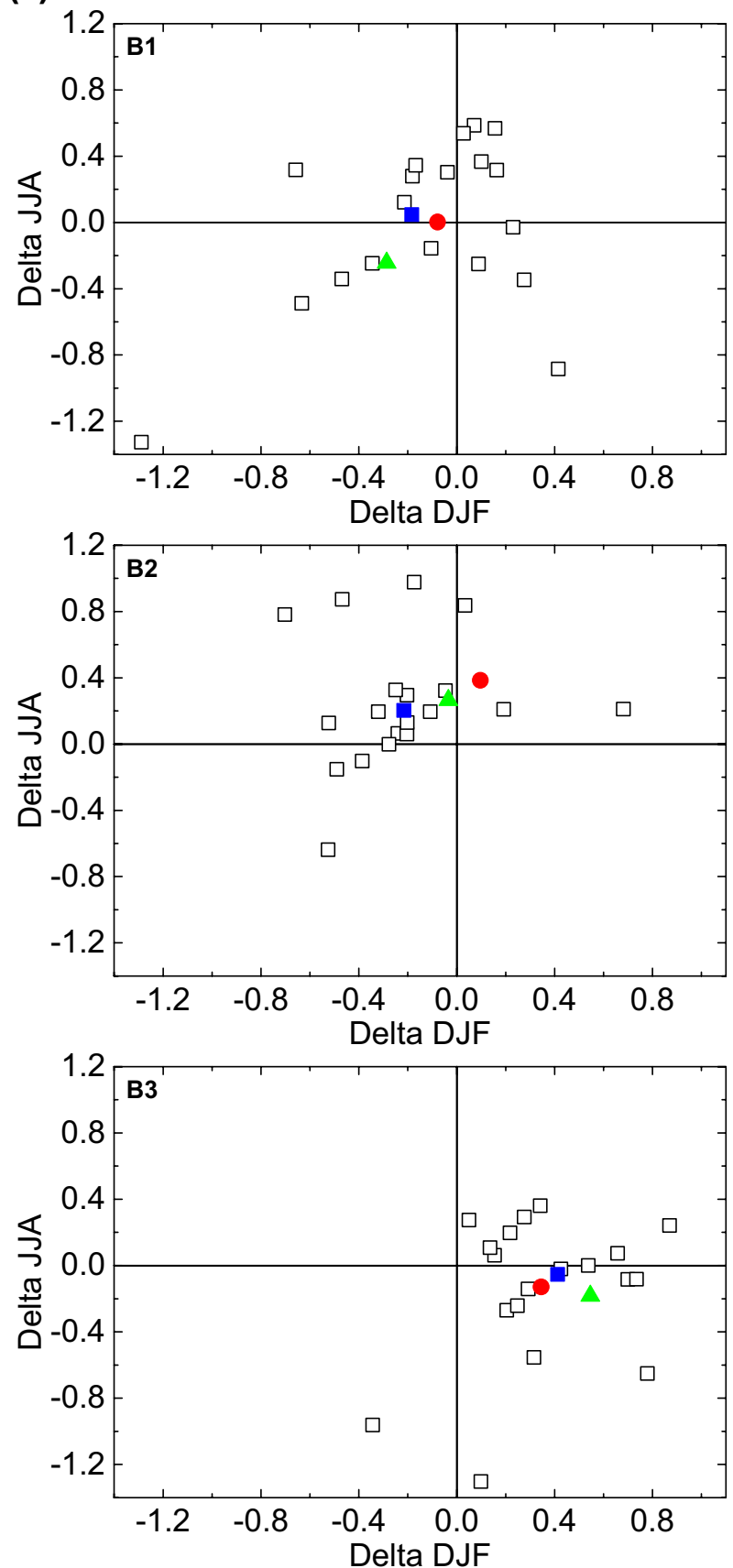

(b)
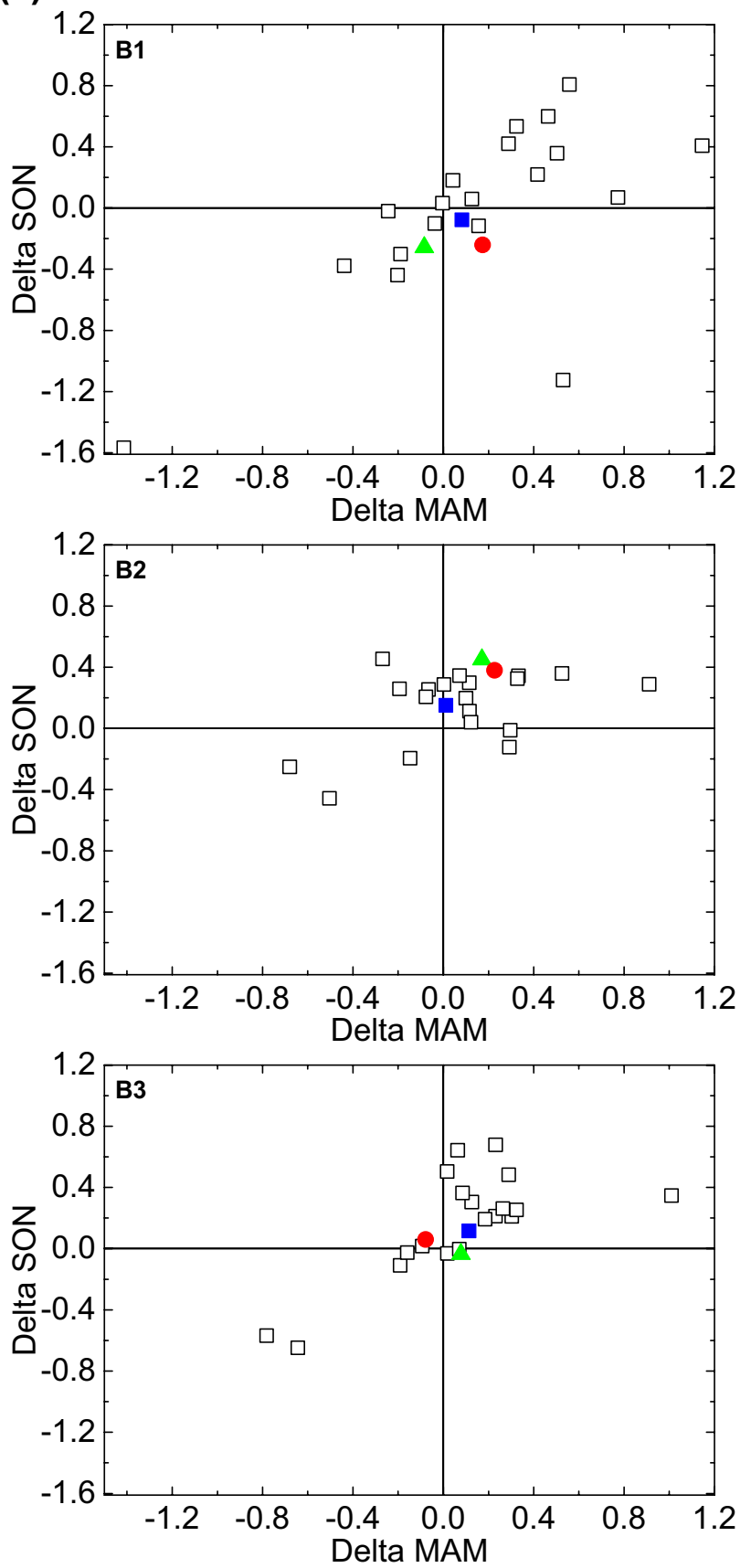

ROM_U ROM_C $\square$ EnsFull $\square$ RCMs 0.44

Fig. 8 Wind speed at 100-m height delta absolute change values averaged over each area (B1, B2 and B3) for the period 2070-2099 with respect to 1976-2005. The delta values are calculated for the seasonal values in a austral summer (DJF, $\mathrm{X}$ axis) and winter (JJA, Y axis) and

(SST), which feedbacks negatively with the near-surface wind speed, resulting in a decrease of the wind speed in the maritime atmospheric boundary layer (MABL) (Lima et al. 2019a). During the remaining seasons, the projected wind b in autumn (MAM, $\mathrm{X}$ axis) and spring (SON, $\mathrm{Y}$ axis). Results are given by both ROM simulations (uncoupled and coupled), CORDEXAfrica multi-model ensemble (EnsFull) and individual RCMs (RCMs $0.44)$

energy density has small changes in the uncoupled ROM run. The same does not happen in the coupled ROM run and in the EnsFull, where a decrease between - 20 and $-26 \%$ is projected to occur, particularly during winter and spring 
seasons. Offshore Namibia, during summer, the projected changes in the uncoupled and coupled ROM simulations are not statistically significant, although the EnsFull presents a negative relative change around $-12 \%$. In the area (B1), the EnsFull projected slight changes, however there is a large spread between individual models, revealing an unclear projected change signal in all seasons.

The increase of the offshore wind resource potential is related to the strengthening of the Benguela CLLJ offshore Namibia and west South Africa (Lima et al. 2019a). Also, the coastal areas where the potential is larger agrees with the areas with higher Benguela CLLJ frequency of occurrence. An overall analysis of the projected changes shows a north-south migration of the offshore wind resource. The analysis also reveals increases in two coastal areas, offshore Namibia and west South Africa, where the industry of wind harvesting can reach higher energy production. To further assess the annual cycle of the wind energy density for present and future climates, the annual cycle for present and future climates, as well as the relative differences, are depicted in Fig. 9 for the three areas defined in Fig. 1c.

In the northernmost area (B1) the values of wind energy density are higher between July and October, closer to 1000 $\mathrm{Wm}^{-2}$, decreasing to $\sim 200 \mathrm{Wm}^{-2}$ during January and February, which reveals a strong annual cycle (Fig. 9a). As illustrated through the projected changes of the annual mean (Fig. 7), the annual cycle shows an overall decrease of the wind energy density in the northern area (B1; Fig. 9b). The projected relative reduction of wind energy density is more pronounced in the months where its values are lower. For the RCP8.5 scenario, the EnsFull show a smaller decrease of the offshore resource than both ROM runs. The coupled ROM run has a positive projected change in March and July, reaching $+12 \%$ in the latter, while no significant change is projected by the EnsFull during winter months. In the first three months of the year, the uncoupled ROM simulation presents a strong reduction of energy density, which can reach $-23 \%$, whilst the coupled ROM run and EnsFull has a smaller decrease, closer to $-10 \%$. Regarding the central area (B2), spring and summer months have associated the highest values of wind energy density, ranging from 800 to $1000 \mathrm{Wm}^{-2}$. The coupled and uncoupled ROM simulations projected positive changes of wind energy density, except in February, March and November, whilst the EnsFull for the RCP8.5 scenario shows negative anomalies from October to March and positive during the remaining months. The west South Africa (southernmost area; B3) has the lowest annual variability comparatively with the other two areas. The uncoupled and coupled ROM simulations present rather similar annual cycle, with positive changes in almost all the months of summer and spring, and the opposite during autumn and winter. The EnsFull RCP8.5 shows positive anomalies in all months, except from July to September. In all areas, the EnsFull RCP4.5 scenario follows the climate change signal projected by the EnsFull RCP8.5, although with lower anomalies, ranging from -10 and $+10 \%$. In general, the climate change signal is rather similar between ROM simulations and EnsFull, however with differences in the magnitude of changes.

Along the Benguela EBCS, the Benguela CLLJ occurs virtually the entire year, and is characterised by strong wind speed within or at the top of the MABL temperature inversion. The most predominant height of the jet wind maxima occurrence is around $360 \mathrm{~m}$ (Lima et al. 2019b). Since the Benguela CLLJ occurs with a frequency around $50 \%$ in present climate [Fig. 4 in Lima et al. (2019b)] and it is projected to increase towards the end of the twenty-first century [Fig. 6 of Lima et al. (2019a)], it is expected that the wind energy density will have larger values at higher altitudes than at $100 \mathrm{~m}$. Presently, the hub-height of the floating turbines is around $100 \mathrm{~m}$. Nevertheless, the development of offshore floating hub turbines placed at higher heights (e.g. $250 \mathrm{~m}$ ) is under consideration for the near future, to increase the energy production capacity and to reduce the costs associated with offshore wind energy (Wiser et al. 2011). To analyse the differences in wind energy density between the $250 \mathrm{~m}$ and $100 \mathrm{~m}$ for the end of the twenty-first century (RCP8.5), Fig. 10 displays the relative difference between the wind energy density at these two heights, for both ROM simulations (the EnsFull is excluded since the wind interpolation is through logarithm method). As expected, there is an overall increase of the wind energy density in all areas, more prominent near the coastal regions. Along the Angola's coast, the differences are lower than $10 \%$ for the uncoupled ROM and can reach $20 \%$ during winter and spring in the coupled ROM run. Offshore Namibia and west South Africa, there is an increase in the potential of offshore wind resource at $250 \mathrm{~m}$, larger in the coupled ROM run. During summer, the differences can reach 50\% in the coupled ROM and 30\% in the uncoupled ROM simulation. In the remaining seasons, near coastal regions of offshore Namibia and west South Africa, the differences can reach $40 \%$ in the coupled ROM run and $20 \%$ in the uncoupled ROM simulation. These high values of wind energy density offshore Namibia and west South Africa are in agreement with the future projections of an increase of the Benguela frequency of CLLJ occurrence.

\section{Discussion and conclusion}

The present challenge of reduce greenhouse gas emissions to the atmosphere has led to an increase of renewable energy development in the last decades. As the onshore locations for wind farms becomes scarce, technological development renders offshore wind energy increasingly more attractive. 
(a)
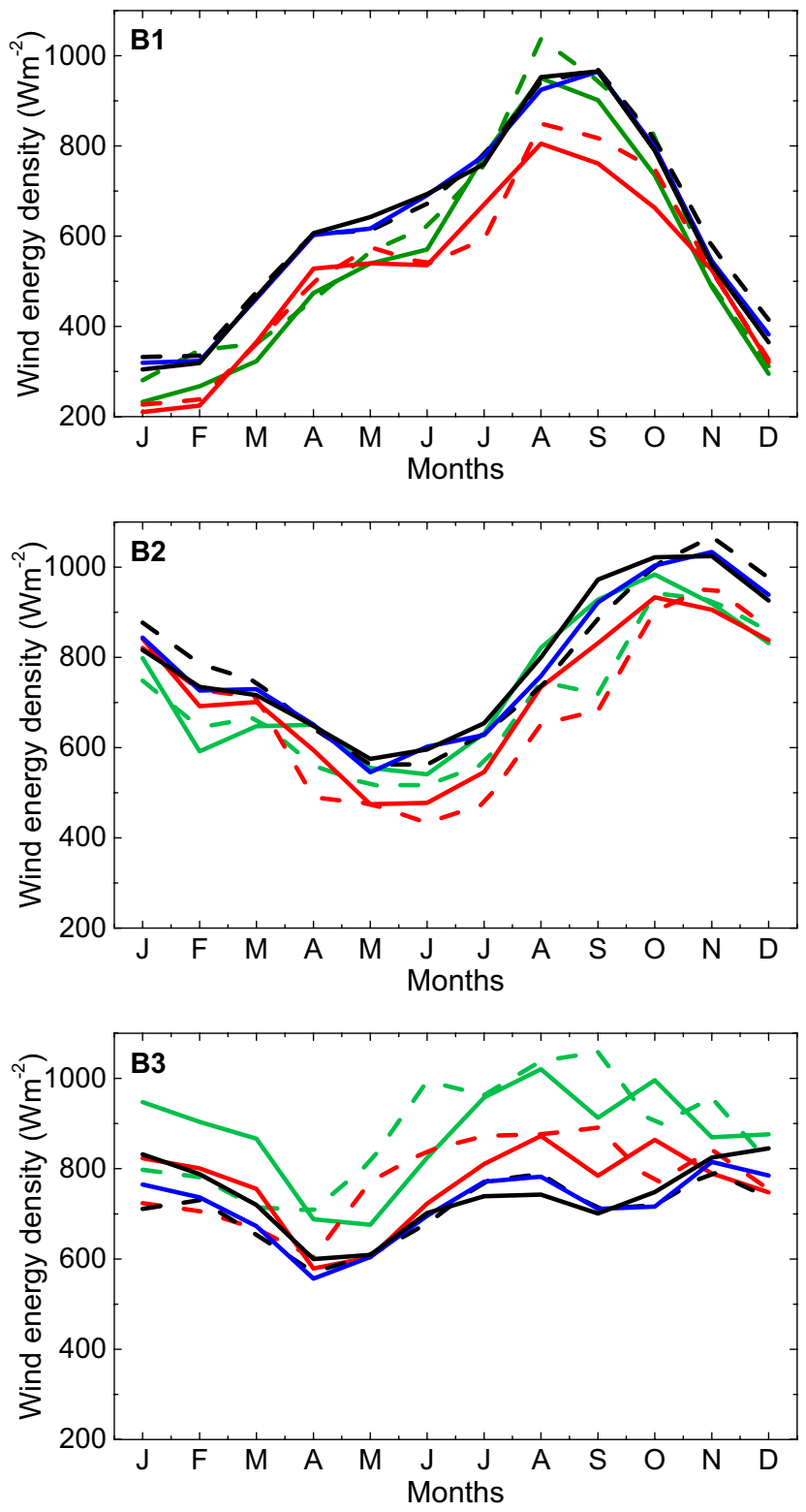

$$
\begin{aligned}
& - \text { ROM_U - Hist } \\
& - \text { ROM_U - RCP8.5- - EnsFull - Hist } \\
& - \text { ROM_C - Hist EnsFull - RCP4.5 } \\
& \text { ROM_C - RCP8.5—EnsFull - RCP8.5 }
\end{aligned}
$$

Fig. 9 a Annual cycle of the wind energy density at $100 \mathrm{~m}$ height for the historical and the end of the twenty-first century climate following the RCP4.5 and RCP8.5 and b respective relative change (2070-2099

However, global warming is associated with changes of the wind patterns, as in the EBCS regions. Therefore, it is crucial to investigate the impact of the climate change on the (b)
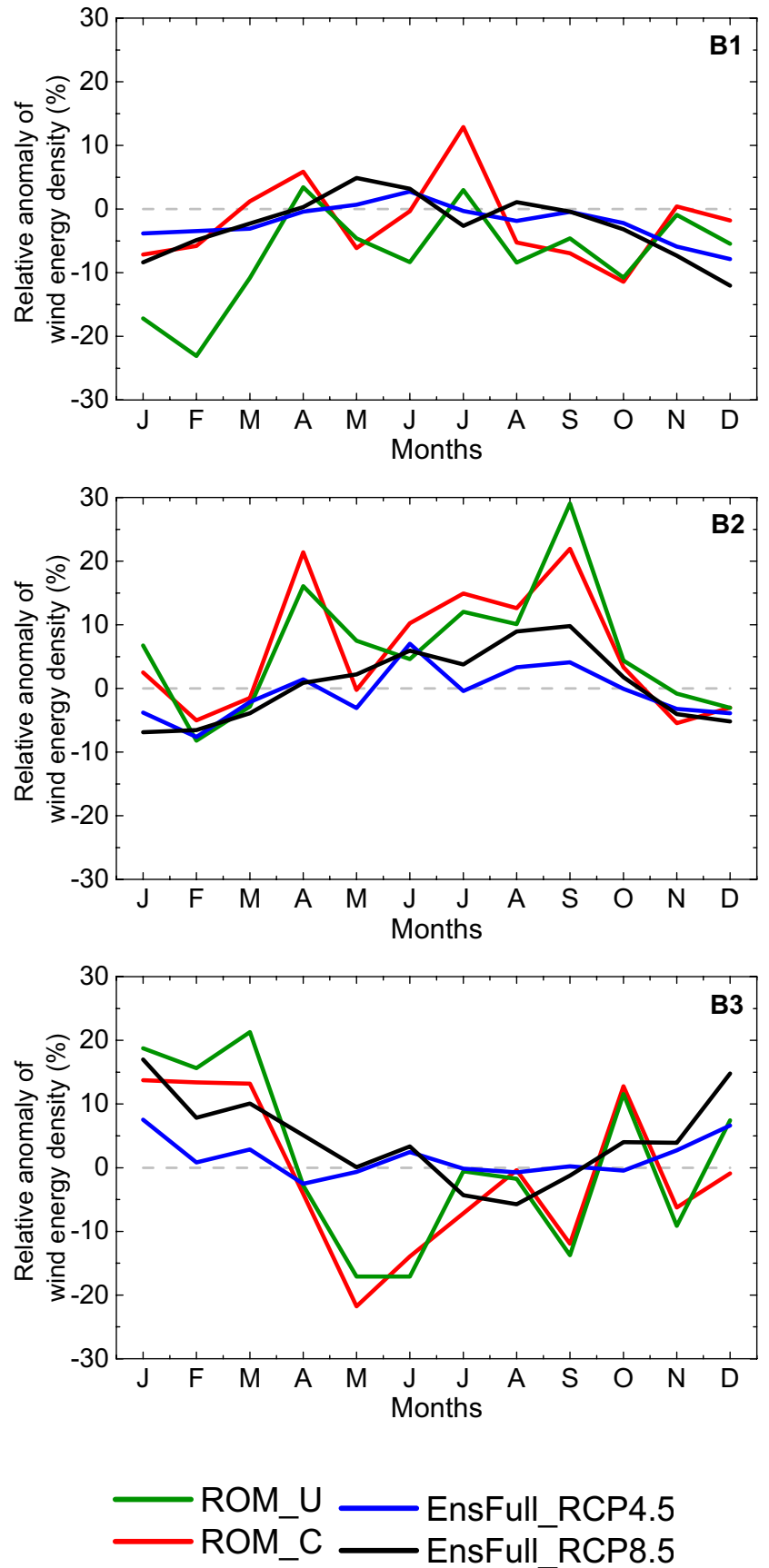

minus 1976-2005)/1976-2005, for areas B1, B2 and B3 (red boxes in Fig. 1c) from uncoupled and coupled ROM simulations and CORDEX-Africa multi-model ensemble

offshore wind resources and its evolution throughout the twenty-first century.

The characterisation of the present and future offshore wind resource in the Southwestern African offshore region 


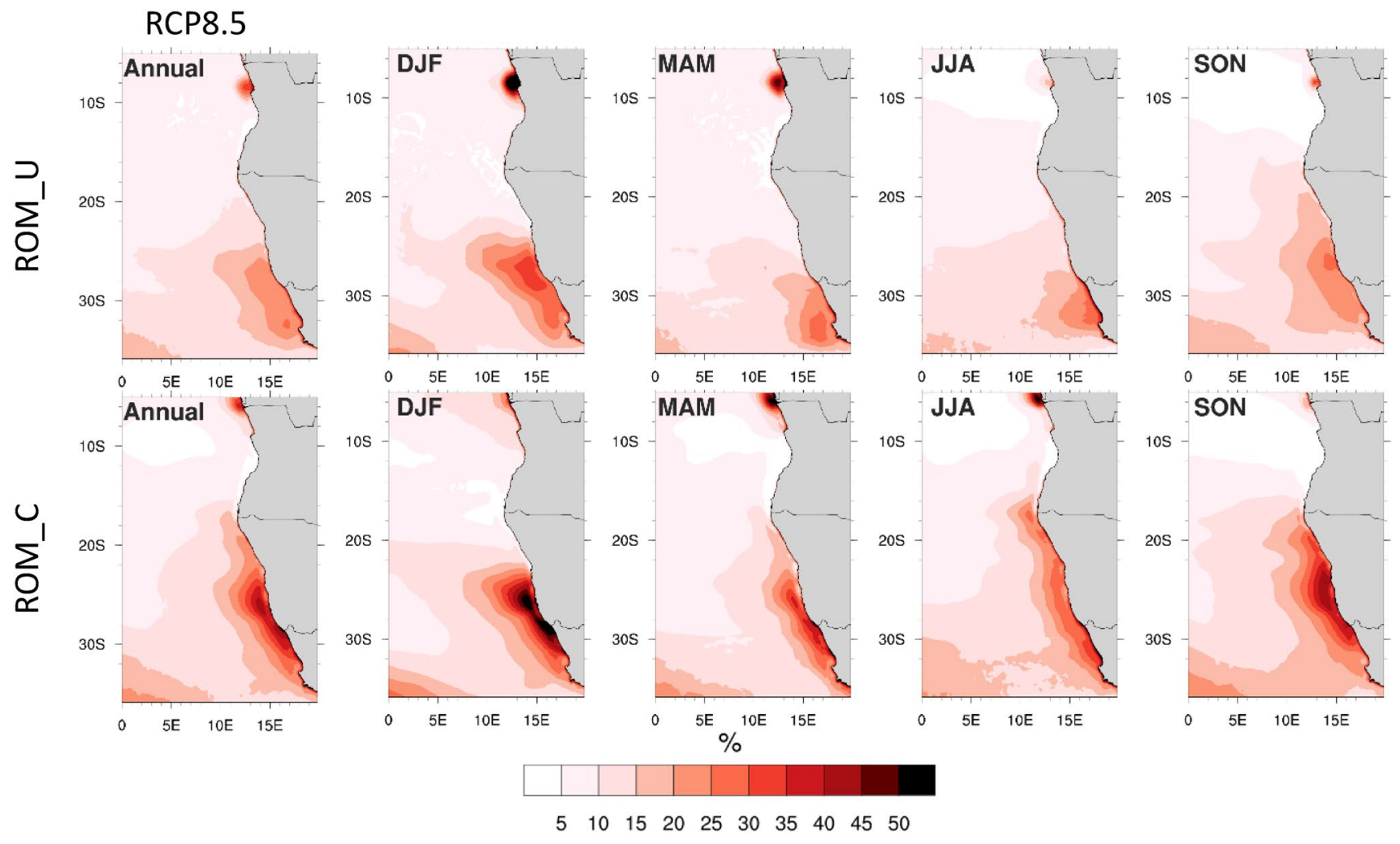

Fig. 10 Relative changes for annual and seasonal mean of wind energy density between 250 and 100 m for the end of the twenty-first century $\left(\boldsymbol{E}_{250 \mathrm{~m}}\right.$ minus $\left.\boldsymbol{E}_{100 \mathrm{~m}}\right) / \boldsymbol{E}_{100 \mathrm{~m}}$ for the uncoupled and coupled ROM simulations

was presented for the first time in the current study. The analysis of the future climate was performed for middle and end of the twenty-first century. Two ROM simulations in an uncoupled atmosphere mode and coupled atmosphere-ocean mode at $25 \mathrm{~km}$ resolution, and a CORDEX-Africa multimodel ensemble built with $19 \mathrm{RCMs}$ at $0.44^{\circ}$ horizontal resolution, were used. This allowed the analysis of model's performance and the exploration of uncertainties of the future projections, giving robustness to the study.

For present climate, the Southwestern African offshore region revealed great availability of wind resource. The wind energy density has a seasonal cycle associated to the wind speed variability. The higher values of wind speed and therefore higher wind energy available, were found in regions where the Benguela CLLJ is more frequent and stronger. The wind energy density showed similar spatial patterns between both ROM simulations and the EnsFull. Offshore Namibia and west South Africa, the wind energy density was shown to have values higher than $700 \mathrm{Wm}^{-2}$, reaching 1500 $\mathrm{Wm}^{-2}$ during spring and summer. Along the Angola's coast, the wind speed is weaker, leading to lower available wind energy density, with values not reaching $500 \mathrm{Wm}^{-2}$. Nevertheless, the Southwestern African offshore region revealed a greater potential for the offshore wind resource.
The projected changes of the 100-m wind speed showed a similar signal between models. The warming climate impacts significantly on the expected future offshore wind energy resource in the studied area. An increase in the wind energy density is projected to occur offshore west South Africa during summer, for the EnsFull in both greenhouse gas emission scenarios (RCP4.5 and RCP8.5), throughout the twenty-first century enhancing at the end of the century. In late twenty-first century, the EnsFull, following the RCP4.5 scenario, projects relative changes of the wind energy density of around +4 to $+8 \%$. Regarding the RCP 8.5 scenario, the EnsFull increases reach $+24 \%$ offshore west South Africa during summer. The expected enhancement of the wind energy density offshore west South Africa is related to the south-easterly shift of the South Atlantic anticyclone, which intensifies the flow along the west South Africa coast (Lima et al. 2019a). This also enhance the conditions for the Benguela CLLJ occurrence, with higher wind speeds in altitude. Future projections of the wind energy density in this region are similar in both ROM simulations. The variability of the wind resource is lower relatively to the variability in the coasts of Namibia and Angola, with an average oscillation of about $550-1000 \mathrm{Wm}^{-2}$ along the year. Along the coast of Namibia, during winter, a projected increase of the wind resource of around $+18 \%$ is expected. A reduction 
in wind energy availability is projected to occur along the coast of Angola throughout the entire year. The projected increase of the SST in this region may lead to a decrease of the wind speed near-surface. The projections offshore Angola revealed some differences in magnitude between simulations, although with the same change signal. Both coupled ROM and EnsFull showed a decrease of about $-20 \%$ and $+26 \%$ during winter and spring. The uncoupled ROM run presented a strong decrease of the offshore wind energy density reaching $-32 \%$, whilst in the coupled ROM and EnsFull do not exceed - 20\%.

Overall, the uncoupled ROM simulations showed lower values of wind speed, and consequently, lower values of wind energy density offshore the Southwestern African region. This difference in wind speed field between both ROM simulations can be related to the air-sea interactions, which play an important role in EBCS (Sein et al. 2015; Lima et al. 2019a; Soares et al. 2019a). In the case of the coupled ROM simulation, the SST stems from the ocean model representation of ocean dynamics and atmosphere-ocean interaction processes, while in the uncoupled simulation it is derived from the GCM. Consequently, the coupled ROM run has a higher SST resolution than in the uncoupled, leading to a better description of the across-shore SST gradients. Along the coast, the land-sea thermal contrast is larger in the coupled ROM than in the uncoupled, resulting in strong wind speeds in the MABL (Lima et al. 2019a). However, in the open ocean, the St. Helen anticyclone is broader and more intense in the coupled run, leading to lower wind speeds than in the uncoupled one.

The results presented in this study showed a relevant improvement in the knowledge of offshore wind resource using a coupled atmosphere-ocean simulation, which can be applied to other EBCS regions. In line with this, a state-of-the-art climate change assessment of offshore wind resource, featuring model uncertainty and using coupled atmosphere-ocean models, would require more simulations forced by different GCMs. Although the climate change signal between the EnsFull and ROM simulations is similar, there are some differences in what regards the magnitude, which can be related to the different GCMs and RCMs used.

The future evolution of offshore floating hub turbines placed at higher altitudes (e.g. $250 \mathrm{~m}$ ) may benefit this region, potentially increasing the amount of energy to be produced. In the Southwestern African offshore region, due to the presence of the Benguela CLLJ, the wind speed is stronger at higher altitudes than $100 \mathrm{~m}$. Along Namibia and west South Africa coasts, the wind energy density at $250 \mathrm{~m}$ showed differences between +30 and $+50 \%$ relative to wind energy density at $100 \mathrm{~m}$. At $250 \mathrm{~m}$ of height, close to the frequent altitude of Benguela CLLJ occurrence, the available energy is higher than at $100 \mathrm{~m}$ height, reaching $2400 \mathrm{Wm}^{-2}$.
The recently released reanalysis data from the ECMWF, the ERA5 at $0.285^{\circ}$ horizontal resolution with 137 model levels, allows a global characterisation of the renewable offshore wind energy and will be investigated in a future research. Also, it would be interesting to explore the impact of the warming climate on global renewable offshore wind energy, using an ensemble of GCMs, under the framework of the CMIP6 project.

Acknowledgements Daniela Lima is supported by FCT through a doctoral grant PD/BD/106008/2014, within the EarthSystems Doctoral Program of the Faculty of Sciences of the University of Lisbon. The work on this study was pursuit in the framework of the SOLAR project (PTDC/GEO-MET/7078/2014) and LEADING project (PTDC/ CTA-MET/28914/2017), financed by the Portuguese Foundation for Science and Technology. This work was also supported by FCT through project UIDB/50019/2020 - Instituto Dom Luiz. Dmitry Sein is supported by the EC Horizon 2020 project PRIMAVERA under the grant agreement 641727 and the state assignment of the Ministry of Science and Higher Education of Russia (theme 0149-2019-0015). The model simulation was performed at the German Climate Computing Center (DKRZ). The authors also thank the climate modelling groups (listed in Table 1) for producing and making available their model output, available in the Portal Earth System Grid Federation (http://esg-dn1. nsc.liu.se/esgf-web-fe/live).

\section{References}

Atlas R, Hoffman RN, Ardizzone J et al (2011) A cross-calibrated, multiplatform ocean surface wind velocity product for meteorological and oceanographic applications. Bull Am Meteorol Soc 92:157-174. https://doi.org/10.1175/2010BAMS2946.1

Bakun A, Black BA, Bograd SJ et al (2015) Anticipated effects of climate change on coastal upwelling ecosystems. Curr Clim Change Rep 1:85-93. https://doi.org/10.1007/s40641-015-0008-4

Barthelmie RJ, Pryor SC (2014) Potential contribution of wind energy to climate change mitigation. Nat Clim Change 4:684-688. https ://doi.org/10.1038/nclimate2269

Beardsley RC, Dorman CE, Friehe CA et al (1987) Local atmospheric forcing during the coastal ocean dynamics experiment 1 . A description of the marine boundary layer and atmospheric conditions over a Northern California upwelling region. J Geophys Res 92:1467-1488

Careto JAM, Cardoso RM, Soares PMM, Trigo RM (2018) LandAtmosphere coupling in CORDEX-Africa: hindcast regional climate simulations. J Geophys Res Atmos 123:11048-11067. https ://doi.org/10.1029/2018JD028378

Carvalho D, Rocha A, Gómez-Gesteira M, Silva Santos C (2014) Offshore wind energy resource simulation forced by different reanalyses: comparison with observed data in the Iberian Peninsula. Appl Energy 134:57-64. https://doi.org/10.1016/j.apene rgy.2014.08.018

Christensen OB, Drews M, Christensen JH, Dethloff K, Ketelsen K, Hebestadt I, Rinke A (2007) The HIRHAM regional climate model version 5 (beta). Technical Report 06-17, pp 1-22

EIA (2019) Annual Energy Outlook 2019 with projections to 2050

Fant C, Adam Schlosser C, Strzepek K (2016) The impact of climate change on wind and solar resources in southern Africa. Appl Energy 161:556-564. https://doi.org/10.1016/j.apene rgy.2015.03.042 
Giorgetta MA, Jungclaus J, Reick CH et al (2013) Climate and carbon cycle changes from 1850 to 2100 in MPI-ESM simulations for the Coupled Model Intercomparison Project phase 5. J Adv Model Earth Syst 5:572-597. https://doi.org/10.1002/jame.20038

Giorgi F, Jones C, Asrar GR (2009) Addressing climate information needs at the regional level: the CORDEX framework. WMO Bull $58: 175-183$

GWEC (2010) Global wind 2009 report. Brussels

GWEC (2019) Global Wind Report 2018

Hewitson B, Lennard C, Nikulin G, Jones C (2012) CORDEX-Africa: a unique opportunity for science and capacity building. CLIVAR Exch No 60 17:6-7. https://doi.org/https://doi.org/10.1080/13691 058.2013.807076

Jacob D, Van Den Hurk BJJM, Andræ U et al (2001) A comprehensive model inter-comparison study investigating the water budget during the BALTEX-PIDCAP period. Meteorol Atmos Phys 77:1943. https://doi.org/10.1007/s007030170015

Kaldellis JK, Kapsali M (2013) Shifting towards offshore wind energyRecent activity and future development. Energy Policy 53:136148. https://doi.org/10.1016/j.enpol.2012.10.032

Kalognomou EA, Lennard C, Shongwe M et al (2013) A diagnostic evaluation of precipitation in CORDEX models over Southern Africa. J Clim 26:9477-9506. https://doi.org/10.1175/JCLID-12-00703.1

Kim J, Waliser DE, Mattmann CA et al (2014) Evaluation of the CORDEX-Africa multi-RCM hindcast: systematic model errors. Clim Dyn 42:1189-1202. https://doi.org/10.1007/s00382-013-1751-7

Lima DCA, Soares PMM, Semedo A, Cardoso RM (2018) A global view of coastal low-level wind jets using an ensemble of reanalyses. J Clim 31:1525-1546. https://doi.org/10.1175/ JCLI-D-17-0395.1

Lima DCA, Soares PMM, Semedo A et al (2019a) How will a warming climate affect the Benguela coastal low-level wind jet? J Geophys Res Atmos 124:5010-5028. https://doi.org/10.1029/2018JD0295 74

Lima DCA, Soares PMM, Semedo Á et al (2019b) A climatological analysis of the Benguela coastal low-level jet. J Geophys Res Atmos 124:3960-3978. https://doi.org/10.1029/2018JD028944

Lu X, McElroy MB, Kiviluoma J (2009) Global potential for windgenerated electricity. Proc Natl Acad Sci USA 106:1093310938. https://doi.org/10.1073/pnas.0904101106

Moss RH, Edmonds JA, Hibbard KA et al (2010) The next generation of scenarios for climate change research and assessment. Nature 463:747-756. https://doi.org/10.1038/nature08823

Nikulin G, Jones C, Giorgi F et al (2012) Precipitation climatology in an ensemble of CORDEX-Africa regional climate simulations. J Clim 25:6057-6078. https://doi.org/10.1175/JCLI-D-11-00375 .1

Nogueira M, Soares PMM, Tomé R, Cardoso RM (2019) Highresolution multi-model projections of onshore wind resources over Portugal under a changing climate. Theor Appl Climatol 136:347-362. https://doi.org/10.1007/s00704-018-2495-4

OECD/IEA (2013) Technology Roadmap. Wind energy

Panitz HJ, Dosio A, Büchner M et al (2014) COSMO-CLM (CCLM) climate simulations over CORDEX-Africa domain: analysis of the ERA-Interim driven simulations at $0.44^{\circ}$ and $0.22^{\circ}$ resolution. Clim Dyn 42:3015-3038. https://doi.org/10.1007/s0038 2-013-1834-5

Pryor SC, Barthelmie RJ (2011) Assessing climate change impacts on the near-term stability of the wind energy resource over the United States. Proc Natl Acad Sci 108:8167-8171. https://doi. org/10.1073/pnas.1019388108

Ranjha R, Svensson G, Tjernström M, Semedo A (2013) Global distribution and seasonal variability of coastal low-level jets derived from ERA-Interim reanalysis Global distribution and seasonal variability of coastal low-level jets derived from
ERA-Interim rean. Tellus A Dyn Meteorol Oceanogr 65:1-21. https://doi.org/10.3402/tellusa.v65i0.20412

Reboita MS, Amaro TR, de Souza MR (2018) Winds: intensity and power density simulated by RegCM4 over South America in present and future climate. Clim Dyn 51:187-205. https://doi. org/10.1007/s00382-017-3913-5

Riahi K, Rao S, Krey V et al (2011) RCP 8.5-a scenario of comparatively high greenhouse gas emissions. Clim Change 109:3357. https://doi.org/10.1007/s10584-011-0149-y

Rockel B, Will A, Hense A (2008) The regional climate model COSMO-CLM (CCLM). Meteorologische Zeitschrift, August 25

Samuelsson P, Coauthors (2011) The rossby centre regional climate model rca3: model description and performance. Tellus Ser Dyn Meteorol Oceanogr 63:4-23. https://doi.org/10.111 1/j.1600-0870.2010.00478.x

Sein DV, Mikolajewicz U, Gröger M et al (2015) Regionally coupled atmosphere-ocean-sea ice-marine biogeochemistry model ROM: 1. Description and validation. J Adv Model Earth Syst 7:268-304. https://doi.org/10.1002/2014MS000357

Semedo A, Soares PMM, Lima DCA et al (2016) The impact of climate change on the global coastal low-level wind jets: ECEARTH simulations. Glob Planet Change 137:88-106. https:// doi.org/10.1016/j.gloplacha.2015.12.012

Soares PMM, Cardoso RM, Semedo Á et al (2014) Climatology of the Iberia coastal low-level wind jet: weather research forecasting model high-resolution results. Tellus Ser A Dyn Meteorol Oceanogr 66:1-18. https://doi.org/10.3402/tellusa.v66.22377

Soares PMM, Lima DCA, Cardoso RM et al (2017a) Western Iberian offshore wind resources: more or less in a global warming climate? Appl Energy 203:72-90. https://doi.org/10.1016/j.apene rgy.2017.06.004

Soares PMM, Lima DCA, Cardoso RM, Semedo A (2017b) High resolution projections for the western Iberian coastal low level jet in a changing climate. Clim Dyn 49:1547-1566. https://doi. org/10.1007/s00382-016-3397-8

Soares PMM, Lima DCA, Semedo A et al (2019a) Assessing the climate change impact on the North African offshore surface wind and coastal low-level jet using coupled and uncoupled regional climate simulations. Clim Dyn 52:7111-7132. https:// doi.org/10.1007/s00382-018-4565-9

Soares PMM, Lima DCA, Semedo Á et al (2019b) The North African coastal low level wind jet: a high resolution view. Clim Dyn 53:1211-1230. https://doi.org/10.1007/s00382-018-4441-7

Sydeman WJ, García-Reyes M, Schoeman DS et al (2014) Climate change and wind intensification in coastal upwelling ecosystems. Science 345:77-80. https://doi.org/10.1126/science.1251635

Talley LD, Pickard GL, Emery WJ, Swift JH (2011) Descriptive physical oceanography: an introduction, 6th edn. Academic Press, Cambridge

Tang W, Liu WT, Stiles BW (2004) Evaluation of high-resolution ocean surface vector winds measured by QuikSCAT scatterometer in coastal regions. IEEE Trans Geosci Remote Sens 42:17621769. https://doi.org/10.1109/TGRS.2004.831685

Van Meijgaard E, Van Ulft LH, Van De Berg WJ, Bosveld FC, Van Den Hurk BJJM, Lenderink G, Siebesma AP (2008) The KNMIregional atmospheric climate model RACMO version 2.1

van Vuuren DP, Edmonds J, Kainuma M et al (2011) The representative concentration pathways: an overview. Clim Change 109:5-31. https://doi.org/10.1007/s10584-011-0148-z

Wang D, Gouhier TC, Menge BA, Ganguly AR (2015) Intensification and spatial homogenization of coastal upwelling under climate change. Nature 518:390-394. https://doi.org/10.1038/nature14235

Winant CD, Dorman CE, Friehe CA, Beardsley RC (1988) The marine layer off northern California: an example of supercritical channel flow. J Atmos Sci 45:3588-3605 
WindEurope (2019) Wind energy in Europe in 2018-Trends and Statistics

Wiser R, Yang Z, Hand M, et al. (2011) Wind energy. In: In IPCC special report on renewable energy sources and climate change mitigation. Cambridge University Press, Cambridge and New York

Wiser R, Bolinger M, Barbose G, et al. (2018) 2018 Wind technologies market report

Yamada T, Mellor G (1975) A simulation of the Wangara atmospheric boundary layer data. J Atmos Sci 32:2309-2329. https
://doi.org/10.1175/1520-0469(1975)032\%3c2309:ASOTW A\%3e2.0.CO;2

Publisher's Note Springer Nature remains neutral with regard to jurisdictional claims in published maps and institutional affiliations. 